\title{
WestVirginiaUniversity
}

THE RESEARCH REPOSITORY @ WVU

Graduate Theses, Dissertations, and Problem Reports

2018

\section{Three Essays on Urban and Health Economics}

Hyunwoong Pyun

Follow this and additional works at: https://researchrepository.wvu.edu/etd

\section{Recommended Citation}

Pyun, Hyunwoong, "Three Essays on Urban and Health Economics" (2018). Graduate Theses,

Dissertations, and Problem Reports. 7233.

https://researchrepository.wvu.edu/etd/7233

This Dissertation is protected by copyright and/or related rights. It has been brought to you by the The Research Repository @ WVU with permission from the rights-holder(s). You are free to use this Dissertation in any way that is permitted by the copyright and related rights legislation that applies to your use. For other uses you must obtain permission from the rights-holder(s) directly, unless additional rights are indicated by a Creative Commons license in the record and/ or on the work itself. This Dissertation has been accepted for inclusion in WVU Graduate Theses, Dissertations, and Problem Reports collection by an authorized administrator of The Research Repository @ WVU.

For more information, please contact researchrepository@mail.wvu.edu. 


\title{
Three Essays on Urban and Health Economics
}

\author{
Hyunwoong Pyun \\ Dissertation submitted to the \\ College of Business and Economics \\ at West Virginia University \\ in partial fulfillment of the requirements \\ for the degree of \\ Doctor of Philosophy \\ in \\ Economics \\ Brad R. Humphreys, Ph.D., Chair \\ Jane E. Ruseski, Ph.D. \\ Joshua C. Hall, Ph.D. \\ Barbara Apostolou, Ph.D. \\ Department of Economics \\ Morgantown, West Virginia \\ 2018
}

Keywords: Major League Baseball, externality, Uniform Crime Report, vehicle-miles traveled, smoking cessation, British Household Panel Survey 


\section{Abstract \\ Three Essays on Urban and Health Economics \\ Hyunwoong Pyun}

The dissertation covers two topics. The first in two essays explore the causal negative effect of professional sporting events on a hosting city. The Last essay tries to estimate the causal effect of smoking cessation on health outcome. In the first essay, I examine the impact of Major League Baseball (MLB) games on crime in a host city using the Washington Nationals case, which moved from Montreal, Canada to Washington DC in 2005, as a natural experiment. To address endogeneity concerns, I apply a synthetic control method with using 21 large cities which host an MLB team as a "donor pool" and employs a triple difference-indifference approach to estimate the change in crime before and after the Nationals coming, between MLB season and off-season, and Washington DC and the synthetic Washington. With monthly crime data from the Uniform Crime Report, only assaults increased by 7 to $7.5 \%$ annually after the Nationals moved to DC; other crimes were unchanged. This result is supported by statistical significance and in-space placebo tests, and several alternative specifications in robustness check. Little to no evidence of a causal relationship between MLB games and other types of crime. The second essay, jointly with Dr. Brad Humphreys, looked at the relationship between MLB games and traffic congestion. No empirical evidence currently exists linking sporting events to local traffic conditions. This chapter analyzes urban mobility data from 25 US metropolitan areas with MLB teams over the period 1990 to 2014 to assess the relationship between local traffic and MLB games. Instrumental variable regression results indicate MLB attendance causes increases in local vehicle-miles traveled. At the sample average attendance of 2.8 million, average daily vehicle-miles traveled increases by about $0.5 \%$ or $1.5 \%$ on a game day in cities with MLB teams. Traffic congestion increases by $2 \%$, suggesting that MLB games generate congestion externalities. The last essay explores the causal effect of smoking cessation on health outcome. While negative impacts of smoking on health are well-known, assessing the effect of smoking cessation on health is difficult due to self-selection problems. I address this self-selection using propensity score matching. Using a rich longitudinal data set from the British Household Panel Survey, this chapter finds 5 to 6 percentage point (8\%) increases in the probability of an individual reporting good health status among quitters compared to inconsistent smokers. Respiratory problems decline by $30 \%$ from the average. The estimated effect of quitting on health diminishes with the number of cigarettes smoked before quitting and smoking tenure. 


\section{Acknowledgements}

After a long journey and completing the Ph.D. program, writing this section is the final touch on the journey. It has been a meaningful period of learning valuable lessons, not only in academia, but also in my life. I would like to express my deepest appreciation to the people who have helped and encouraged me to enjoy the journey.

I appreciate my advisor and dissertation committee chair, Dr. Brad R. Humphreys. He has taught me valuable life lessons, and how to enjoy research and scholarship. Without his great guidance, I would not be able to successfully complete my dissertation and enjoy the Ph.D. life.

In addition, I truly appreciate my dissertation committee members, Dr. Jane Ruseski, Dr. Joshua Hall, and Dr. Barbara Apostolou for their encouragement, wisdom, and valuable inputs on my dissertation. I also thank to Dr. Dennis Coates and Dr. Daniel Grossman for their service as a former dissertation committe member.

Finally, I want to acknowledge all the support and love from the friends I made in my time at this program. Amir and Izabella, Patrick, Yang, and all the rest, thank you all.

The first chapter is the pre-peer reviewed version of the following article: Springer, Pyun, H. (2018). Exploring causal relationship between Major League Baseball games and crime: a synthetic control analysis. Empirical Economics, 1-19.

(https://doi.org/10.1007/s00181-018-1440-9).

The second chapter is the pre-peer reviewed version of the following article: Humphreys, B. R., \& Pyun, H. (2017). Professional sporting events and traffic: Evidence from US cities. 
Journal of Regional Science., which has been published in final form at https://doi.org/10.1111/jors.12389. This article may be used for non-commercial purposes in accordance with Wiley Terms and Conditions for Use of Self-Archived Versions. 


\section{Contents}

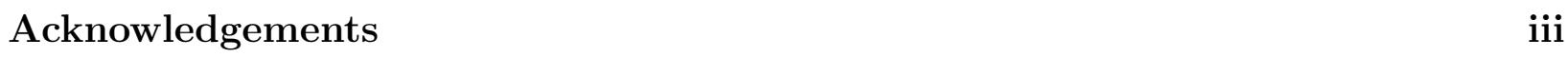

List of Figures $\quad$ vi

List of Tables $\quad$ vii

1 Exploring Causal Relationship between Major League Baseball Games and Crime: A Synthetic Control Analysis

1.1 Introduction . . . . . . . . . . . . . . . . . . . . 1

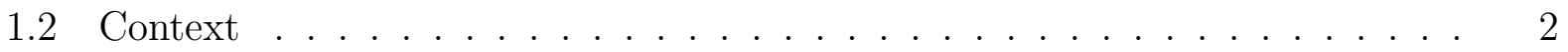

1.3 Empirical Analysis . . . . . . . . . . . . . . . . . . . . 5

1.3.1 Sample and Data . . . . . . . . . . . . . . . . 5

1.3.2 Synthetic Control Method . . . . . . . . . . . . . . . 6

1.3.3 Triple Difference-in-Difference Model . . . . . . . . . . . . . . . . 7

1.3 .4 Inference . . . . . . . . . . . . . . . . . . . . 8

1.4 Results . . . . . . . . . . . . . . . . . . . . . . . . 9

1.5 Robustness Check . . . . . . . . . . . . . . . . . . . . . . . . . . . . . . . . . . 11

1.6 Conclusion . . . . . . . . . . . . . . . . . . . . . 13

2 Professional Sporting Events and Traffic: Evidence from US Cities 21

2.1 Introduction . . . . . . . . . . . . . . . . . . . . . 21

2.2 Sports and Traffic . . . . . . . . . . . . . . . . . . . 23

2.3 Determination of Vehicle Miles Traveled . . . . . . . . . . . . . . . . . . . 25

2.4 Empirical Analysis . . . . . . . . . . . . . . . . . . . . . . . . . . . . . . . . . . . . . .

2.4.1 Data Description . . . . . . . . . . . . . . . . . . 29

2.4 .2 Empirical Model . . . . . . . . . . . . . . . . . . 31

2.4 .3 Results . . . . . . . . . . . . . . . . . . . 33

2.4 Robustness Checks . . . . . . . . . . . . . . . . . 37

2.5 Conclusions . . . . . . . . . . . . . . . . . . . . . . . . . . . . . 38

3 The Effect of Smoking Cessation on Health Outcomes: Evidence from the British Household Panel Survey $\quad 45$

3.1 Introduction . . . . . . . . . . . . . . . . . . . . . . 45

3.2 Literature Review . . . . . . . . . . . . . . . . . . . . . . . 47

3.3 Data . . . . . . . . . . . . . . . . . . . . . . 49 
3.4 Empirical Methods . . . . . . . . . . . . . . . . . . . . 50

3.4.1 Definition of Treatment and Control Groups . . . . . . . . . . 50

3.4 .2 Propensity Score Matching . . . . . . . . . . . . . . . . . . 51

3.4.3 Difference-in-Differences Model . . . . . . . . . . . . . . . 53

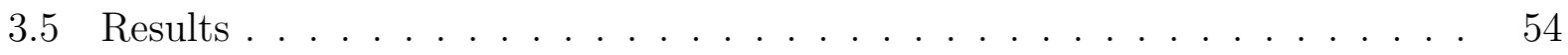

3.6 Robustness Checks . . . . . . . . . . . . . . . . . . . . 55

3.7 Discussion . . . . . . . . . . . . . . . . . . . 56

3.8 Conclusion . . . . . . . . . . . . . . . . . . . . . . . . . . . . . . 58 


\section{List of Figures}

1.1 Changes in Crime: Washington and Synthetic Washington, by Crime Category 15

1.2 Cumulative Distribution of Average Treatment Effects, by Crime Category . 16

2.1 Supply, Demand, and Equilibrium VMT . . . . . . . . . . . . . . 40

3.1 Changes in Health Outcomes . . . . . . . . . . . . . . . . . . . 60

3.2 Hypothetical Disease Incidence Rates for Current, Former and Never Smokers, by Age . . . . . . . . . . . . . . . . . . . 61 


\section{List of Tables}

1.1 General Characteristics of Sample Cities . . . . . . . . . . . . . . . 17

1.2 Estimated Weight from Synthetic Control, by Crime Category . . . . . . . . 18

1.3 Summary Statistics of Washington and Synthetic Washington . . . . . . . . 18

1.4 Triple Difference-in-Difference Result . . . . . . . . . . . . . . . . . . . . . . 19

1.5 Robustness Check . . . . . . . . . . . . . . . . . . . . . . . 20

2.1 Summary Statistics . . . . . . . . . . . . . . . . . . . . . . . . 41

2.2 Regression Results, Dependent Variables: Miles Traveled and Delay . . . . . 42

2.3 Regression Results, Dependent Variable: Interstate and Arterial Miles Traveled 43

2.4 Robustness Checks - IV Estimator . . . . . . . . . . . . . . . . . . . . . . . 44

3.1 Summary Statistics - Smoking behavior 1999-2008 . . . . . . . . . . . . . . 62

3.2 Summary Statistics - Matching Covariates in 2000 . . . . . . . . . . . . . 63

3.3 Difference-in-Differences Results . . . . . . . . . . . . . . . . . . . . 64

3.4 Robustness Check . . . . . . . . . . . . . . . . . . . . . . . 64 


\section{Chapter 1}

\section{Exploring Causal Relationship}

\section{between Major League Baseball \\ Games and Crime: A Synthetic Control Analysis}

\subsection{Introduction}

To attract a professional sports franchise into a city, or to keep an existing franchise, public subsidization for new stadium/arena construction is common in the United States. After 2000, 15 new Major League Baseball (MLB) stadiums were constructed, involving an average of $\$ 520$ million in public funding (National Sports Law Institute of Marquette University Law School, 2013). In 2005, the Montreal Expos moved to Washington DC and were renamed the Washington Nationals. As part of the move, the DC city government subsidized most of the construction costs, $\$ 796.6$ million, for a new baseball stadium for the Nationals (The Washington Post, 2008).

To justify these subsidies, direct economic benefits would first be considered. Numerous studies have assessed the tangible economic impact of new facilities and teams. Studies on the effect of stadiums and franchises mostly find little to no increases in employment, personal income, or personal income per capita (Baade, 1996; Coates and Humphreys, 2002, 
2003a; Siegfried and Zimbalist, 2000). Research on intangible benefits, such as civic pride, followed. Papers on this topic mostly find positive estimates of willingness to pay for intangible benefits, but not enough to cover most construction costs (Johnson et al., 2001; Owen, 2006; Groothuis et al., 2004; Johnson et al., 2007).

Major sporting events are suspected to be associated with crime, and crime is an important social cost, so it is necessary to assess the effect of a professional sports team or a new stadium on crime for validating public subsidies for sports facilities. Studies on this topic are relatively few, and contain mixed evidence on the relationship between sporting events and crime.

This paper examines the extent to which professional baseball games cause more crime in the local area. A natural experiment design is constructed using the Washington Nationals move. By applying a triple difference-in-difference with a synthetic control method, and using monthly data from Uniform Crime Report (UCR), this paper finds little evidence supporting a causal relationship between MLB games and crime in DC, except for the case of assaults. The move of the Nationals to Washington DC did not generally increase crime in the area.

\subsection{Context}

Recent papers on the relationship between crime and sporting events reflect the concentration of crime on game day in host cities. Rees and Schnepel (2009) report increases in assault, vandalism, arrests for disorderly conduct, and arrests for alcohol-related offenses on college football game days. Using similar data, Card and Dahl (2011) show that upset losses in National Football League (NFL) games lead to $10 \%$ increases in incidents of domestic violence; Kalist and Lee (2016) report that NFL home games are associated with increases in total crime, and financially motivated crime. Using hourly data before and after soccer matches, Munyo and Rossi (2013) report that frustration from match results increases violent crime in Uruguay. Marie (2016) finds increases in property crime on soccer match days in London, England.

As regression-based estimates do not consider the case of absence of sporting events (or 
teams) in a local community, it is difficult to assess the causal relationship between crime and sports events in the results discussed above. For example, findings in this literature might only reflect the temporal concentration of crime on a game day. If a city does not host any games (i.e. a city does not have a team), criminal activities might spread out on non-game days, resulting in no actual change in crimes committed.

Some of studies above also show indirect effects of sporting events on crime. Emotional triggers, based on reference-dependent preference models with loss averse agents, predict that upset losses generate frustration in fans and make them commit more crimes (Rees and Schnepel, 2009; Card and Dahl, 2011; Munyo and Rossi, 2013; Kalist and Lee, 2016). Whether this theory supports a causal relationship between crime and games is unclear. First, while frustration can cause more crime, like the theory above predicts, the assumption that sporting events are the only source for emotional cues is limiting. If any other sources of emotional triggers exist, the number of crimes occurring might not be different if a city loses a sports team, or has no team. Second, most empirical tests of this theory show that only upset losses increase crime; upset losses are systematically rare. Unexpected losses require two conditions: 1) the home team must be better than the opponent, and 2) the home team must lose when the probability of a loss is small. For example, Card and Dahl (2011) analyze 993 NFL games, and only 79 upset losses (about 8\%) exist in this sample. This small number of upset losses represent about 1.2 games per season. Also, using the estimated coefficient and average number of crimes in their data, NFL games are associated with an increase in crime of 0.12 incidents of domestic violence per year. Although their coefficients are statistically significant, it is questionable whether a local government should consider this small increase in crime as a social cost.

Assessing the direct effect of home games on crime represents a better approach to understanding the crime-related social costs of sports. Yu et al. (2016) use the hot spot theory of crime and report a positive effect of home basketball games on robberies; away games do not affect crime. These changes in crime are associated with large crowds attending games and can also be motivated by Becker (1968)'s theory of crime. Criminals might face lower opportunity costs of committing crime on a game day, in terms of identifying victims or escaping police detection by disappearing in the large crowds going to or from the arena. 
Alcohol consumption could be the another key factor explaining increases in crime, as alcohol consumption is associated with sporting events and is also often associated with the commission of crime.

Other motivations for this paper come from studies which fail to find a statistical relationship between crime and sporting events. Billings and Depken II (2011) find no evidence of a relationship between sporting events in Charlotte, $\mathrm{NC}$ and various types of crime ${ }^{1}$. Baumann et al. (2012) use annual crime data, and find little to no evidence that sporting events are associated with either property or violent crime, except during the Olympics Games and the Super Bowl. One possible hypothesis for the finding of no relationship in Baumann et al. (2012) is that the short NFL schedule, only 8 NFL home games are played each season, would not affect annual crime data much. MLB teams usually play 10-15 home games in a month, so changes in monthly crime rates during the MLB season would be easier to detect than the effect of NFL games on annual crime data.

Most similar to this paper is Pyun and Hall (2016), who explore the causal relationship between NFL games and crime using the Detroit Lions as a case study. They find little to no evidence of increases in crime associated with NFL games in the Detroit area, except larceny, but they only concentrate suburban cities in the Detroit MSA due to data limitations.

The identification strategy in this paper is an improvement on studies using annual data (Baumann et al., 2012), but not perfect as the treatment effect applies only to home game days using monthly frequency data. This identification has an advantage as it is possible that some portion of game attendees commit crime before or after game day and these criminal activities will be captured in here, while other studies with daily data cannot. Also, this paper exploits a natural experiment, and tries to take account of the change in crime before and after the Nationals move. ${ }^{2}$ The synthetic control method allows for the construction of a suitable comparison group, which aids in the estimation of the relationship between crime and MLB games.

\footnotetext{
${ }^{1}$ Billings and Depken II (2011) instead find a spatial concentration of crime on event days.

${ }^{2}$ Munyo and Rossi (2013) also exploit natural experiments but they only compare the change in crime between game and non-game days.
} 


\subsection{Empirical Analysis}

\subsubsection{Sample and Data}

After 2000, Washington, DC was the only US city to attract a MLB team to move into the city. The Washington Nationals moved from Montreal, Canada to Washington, DC in 2005. Washington DC represents the treatment city. For a "Donor pool" to construct a synthetic control group, cities with a population more than 300,000 are initially considered. From this group of cities, I select cities with an MLB team for a donor pool for the synthetic control group. ${ }^{3}$ Cities with a population more than 300,000 but without MLB teams were considered as an another dimension of a donor pool, but disregarded./footnoteCities which don't have a MLB team but have at least one sports team were used in Robustness check later. Cities without MLB teams have small populations, or isolated locations, and appear to be quite different from the treatment city. Abadie et al. (2015) recommends restricting the donor pool to be as similar to the case of interest as possible.

The sample period is from 2000 to 2009; this paper employs data 5 years before and after the Nationals' move. Offenses Known and Clearance by Arrest data from the Uniform Crime Report (UCR) ${ }^{4}$ are analyzed. Monthly, city-level data are available for the entire sample period. This paper estimates the effect of MLB games on the following types of crime: actual number of total offenses, total assaults, total simple assaults, total larcenies, and total motor vehicle theft per 100,000 population.

Miami and Tampa in Florida, Minneapolis, MN, New York, NY and Oakland, CA are excluded from the donor pool as these cities did not provide complete monthly data to the UCR. New Orleans, LA is also excluded from the donor pool because of missing values in the data, mostly due to Hurricane Katrina in 2005. There is some variation in the donor pool across each crime category. Chicago, IL was excluded from only the simple assault regressions as Chicago did not provide the number of simple assaults to the UCR.

Demographic and economic variables from all sample cities are used to construct a syn-

\footnotetext{
${ }^{3}$ Cincinnati had population less than 300,000 in 2010, but an average population from 2000 to 2010 greater than 300,000 .

${ }^{4} \mathrm{UCR}$ data are available at https://www.icpsr.umich.edu.
} 
thetic Washington DC for a control group. Total population, percent of population age 18-24, percent of population age 65+, percent of population African American, percent of population Hispanic, percentage of population college graduate or higher, unemployment rate, and median household income are used as predictors of the crime outcome variables of interest. These city level data are from the 2010 U.S. Census. Summary statistics for Washington DC and the sample of donor cities are shown in Table 1.1.

\subsubsection{Synthetic Control Method}

Natural experiments or quasi-experimental studies are useful methods for exploring a causal relationships in economics. However, due to the lack of random sampling and random assignment of treatments, causal results using these methods are often challenged. The synthetic control method is one way to address this problem. This method constructs a synthetic control group from a weighted average of cities in a donor pool, and the synthetic control group will closely resemble the treatment group. Formally, the synthetic control method finds optimal weights for each donor city by minimizing

$$
\sum_{m=1}^{k} v_{m}\left(X_{1 m}-X_{0 m} W\right)^{2}
$$

where $X_{1 m}$ is a vector of predictor variables in a treatment group and $X_{0 m}$ is a $(\mathrm{kxj})$ matrix of the $m^{t h}$ predictor variable for units in the donor pool. $v_{m}$ indicates a weight that reflects the relative importance estimated for the $m^{\text {th }}$ variable. The synthetic control method chooses $W^{*}$, a vector of weights for each unit in the donor pool, that minimizes Equation (1.1) (Abadie and Gardeazabal, 2003; Abadie et al., 2010, 2015). Note that every element in $W^{*}$ is between zero to one and the sum of all elements is one. As discussed above, Washington DC is the treatment city, and the 21 cities with population greater than 300,000 and an MLB team constitute the donor pool. Total population, age 18-24 percentage, age over 65 percentage, Afro-American percentage, Hispanic percentage, percentage of college graduate or higher, unemployment rate, and median income are used for predictor variables.

Usually, papers exploiting a natural experiment define a comparison group using units that do not receive the treatment. In this case, the donor pool is constructed with data from 
units that do not experience some intervention and $W^{*}$ is calculated using pre-intervention data in the synthetic control method. However, to avoid possible problems of heterogeneity among cities and Washington, this paper constructs a donor pool containing cities that already have the treatment (i.e. host an MLB team). Therefore, when constructing a synthetic control group, I use post-intervention data as both Washington and other cities have MLB teams after the Nationals arrived in DC.

\subsubsection{Triple Difference-in-Difference Model}

After applying the synthetic control method, Bohn et al. (2014) and Munasib and Rickman (2015) construct difference-in-difference type estimators to estimate the average treatment effect. This paper applies a triple difference-in-difference model, as the effect of MLB games on crime would manifest differently in 3 dimensions: as before and after moving, Washington DC versus synthetic Washington DC, and in-season and off-season months. Even if MLB games have a causal effect on crime, crime during the off-season will not change after the Nationals move to the city. By using monthly data, this paper can employ these 3 dimensions into a difference-in-difference model and look for more precise evidence of a sport-crime relationship. The basic form of triple difference-in-difference model is

$$
\begin{array}{r}
\text { crime }_{i t}=\beta_{1}+\beta_{2} \text { treat }_{i t}+\beta_{3} \text { post }_{i t} \\
+\beta_{4} \text { seasit }+\beta_{5} \text { treat }_{i t} * \text { post }_{i t}+\beta_{6} \text { treat }_{i t} * \text { seas }_{i t} \\
+\beta_{7} \text { post }_{i t} * \text { seas }_{i t}+\beta_{8} \text { treat }_{i t} * \text { post }_{i t} * \text { seas }_{i t}+u_{i t}
\end{array}
$$

where crime $_{i t}$ indicates the number of crimes per 100,000 committed in city $i$ (either Washington DC or synthetic Washington) in month $t$. As mentioned above, models explaining variation in the monthly number of total offenses, total assaults, total simple assaults, total larcenies, and total motor vehicle thefts are estimated separately. treat $_{i t}=0$ for synthetic Washington and 1 for Washington DC, post $_{i t}=1$ after the Nationals moved to Washington DC. This paper sets April 2005 as the month the move occurred; this is when games were first played in DC. seas ${ }_{i t}=1$ when the MLB season is ongoing. I assume that the MLB season is from April to September. Games in March or October were very rare for the Washington 
Nationals in this period. In the 10 year sample period, the nationals only played 1 game in March and 3 games in October, while actual games played in each month during the season varied from 10 to 15. I ignore a few home games played in March and October./footnoteIn robustness check, I take account these few games in March and October by using the number of games and monthly attendance.

From Equation (1.2), $\hat{\beta}_{8}$ captures changes in crimes committed during the MLB season in Washington DC after the Nationals moved in compared to the synthetic Washington. Therefore, a positive $\hat{\beta}_{8}$ supports the existence of a causal relationship between MLB games and crime.

\subsubsection{Inference}

Abadie and Gardeazabal (2003) and Abadie et al. (2010, 2015) express concern about using traditional statistical inference methods in synthetic control analysis. This concern stems mostly from small sample size problems. For example, Abadie et al. (2010) use only 40 periods (years) and one state as a treatment group. However, because of the availability of monthly data, the sample period here is 120 months, so asymptotic properties of inference methods should be applicable to the estimator of interest. Therefore, I report standard statistical significance measures for estimates from Equation (1.2).

Though this paper has a relatively large sample period, the use of a single treatment city might be problematic for statistical inference. Therefore, I use 'in-space placebo' tests introduced by Abadie and Gardeazabal (2003) and Abadie et al. (2010, 2015). In-space placebos are a method that assigns every city in the donor pool pairwise to the treatment city, constructs a synthetic control comparable with the treatment city, and estimates the average treatment effect ( $\beta_{8}$ from Equation (1.2)). This idea is very similar to the standard concept of statistical significance tests. The P-value for the significant test indicates the probability that the estimator of interest comes from the null hypothesis (no relationship). Here, after re-estimating all placebos, the distribution of the average treatment effects is very similar concept to the distribution under the null hypothesis in a statistical significance test. Therefore, by comparing $\hat{\beta}_{8}$ to this distribution, a p-value can be constructed. This 
paper reports p-values from the distribution of the average treatment effect from in-place placebo testing.

\subsection{Results}

Cities which have a positive weight in the synthetic control method are shown in Table 1.2. Predictor variables comparisons between Washington and synthetic Washington are shown in Table 1.3.

Figure 1.1 shows the graphical analysis of the treatment effect of MLB games on crime. Before analyzing this graph, note that these figures are different from figures presented in other studies with the synthetic control method. As discussed above, I use cities that already had a treatment effect (i.e. MLB teams) as a donor pool, so I match the treatment city and a donor pool with post-intervention data, while other studies use pre-intervention data. Therefore, the $\mathrm{x}$-axis on Figure 1.1 shows a reverse order of time periods. Period 0 indicates the end of the period, December 2009 and period 120 shows the start of the period, January 2000. The vertical dotted line shows the Nationals arrival, and the right (left) hand side from the vertical line shows pre (post)-intervention period. A causal relationship is supported if crime in synthetic Washington is greater than crime in Washington before the Nationals arrived.

Fitting results in the post-intervention period do not look successful compared to the previous studies with the synthetic control. As this paper uses monthly data, which is more volatile than annual data, it is hard to see the trends and how well the synthetic control group matches with the treatment group. I argue that the fitting results show enough common trends to apply the difference-in-difference approach. Committed crime in the postintervention period in Washington DC look more volatile than the synthetic Washington, but the trend, in terms of up and down, looks similar for both.

As I consider the difference between in-season and off-season outcomes, it is hard to capture changes in 3 dimensions in a two-dimensional figure. However, for total assaults and simple assaults, crime in Washington in the pre-intervention period is clearly smaller than crime in synthetic Washington. Changes in total criminal offenses and motor vehicle thefts 
are questionable. For total criminal offenses, it seems that differences between cities remain in the post-intervention period. For motor vehicle theft, crime in Washington is greater than in synthetic Washington in some pre-intervention periods.

Results from the triple difference-in-difference model are shown in Table 1.4. All estimated coefficients, except $\hat{\beta}_{8}$, from Equation (1.2) capture changes in crime which are not related to the Nationals moving to DC. For example, the negative estimated coefficient on treat for all crime categories except motor vehicle thefts indicates Washington has seen a relatively low number of these crime committed compared to synthetic Washington. The estimated coefficient on the variable post for all crime categories is negative and significantly different from zero, which indicates a decrease in crime after the Nationals move in both Washington and synthetic Washington. The effect of weather on crime seems to be captured by the estimated coefficient on seas. As the MLB season usually covers spring to fall, criminal activities would be concentrated in the MLB season and the positive and statistically significant coefficient for all crimes except motor vehicle theft capture this effect.

After taking account of these exogenous effects, the estimated coefficient on the triple difference-in-difference variable (treat $*$ post $*$ seas) reflects the change in crime during the MLB season in Washington DC compared to synthetic Washington after the Nationals moved in. For all crime categories, estimated coefficients are positive but only the estimated coefficient on total assaults and simple assaults are significant at the $5 \%$ level. At the mean of the number of monthly crimes for each category in Washington DC, these coefficients can be translated to a $14 \%$ monthly increase during the MLB season or $7 \%$ annual increase in total assaults, and a 15\% monthly increase during the MLB season, or a $7.5 \%$ annual increases in simple assaults. ${ }^{5}$ In-space placebo tests also support the statistical significance of these two coefficient estimates. The cumulative distribution of treatment effects is shown in Figure 1.2. Both coefficient estimates are the two largest among the estimated treatment effects from the in-space placebo tests.

The treatment effect on total criminal offenses is only significant at the $10 \%$ level, and supported by the in-space placebo test. The estimated effect indicates monthly $7 \%$ increases

\footnotetext{
${ }^{5}$ As the MLB season covers 6 months, I divide the estimated monthly increases by 2 to calculate the annual changes.
} 
in the MLB season or yearly 3.5\% increases in total offenses. For motor vehicle thefts, estimated coefficient is only supported by the in-space placebo test and shows monthly $10 \%$ and yearly $5 \%$ increases.

As this study concentrates on MLB game attendance related crime, and total criminal offenses include many severe crimes such as homicide which are not likely related to sporting events, little to no evidence for increases in total criminal offenses after the arrival of the Nationals is intuitively understandable. For motor vehicle theft as well, mixed results are plausible and might indicate that auto theft is associated with MLB games in a different way.

Changes in the number of total larcenies associated with MLB games are not supported by any analysis above. This result is a bit surprising as some types of larceny, such as pocketpicking and purse-snatching, are plausibly associated with large game attendance. Also, Pyun and Hall (2016) find a weak evidence for decreases in larceny after the Lions move out. No changes in larceny might reflect some unique unobservable feature of Washington DC, not the relationship between crime and MLB games. This limitation cannot be addressed in a single city case study.

Overall, this paper finds evidence for a causal relationship between MLB games and assaults, mixed, inconclusive evidence for a relationship between MLB and total criminal offenses and motor vehicle theft, and no evidence for a relationship between MLB games and larceny.

\subsection{Robustness Check}

In this section, several alternative models are estimated to test the robustness of the main results. In the first two models, alternative average treatment effect (ATE) estimators are used to see whether changes in crime is driven by baseball games or other unobservable factors. Instead of using interactions among treat, post and seas in Equation (1.2), I use the number of home games played in month $t$, and monthly home attendance. These variables have more variation than dummy variable (treat $*$ post $*$ seas in Equation (1.2)), and ATE estimator will capture MLB game specific effect on crime while the original approach 
might contain some other variation which is not related to baseball but exists only during MLB season after the Nationals' move. If ATE from using the number of home games and attendance looks similar to the original one, this concern will disappear.

Also, comparing the results from using the number of games and those from attendance is meaningful. It is uncertain whether the estimated ATE from the original specification comes from game attendance directly, or contains some externalities. If it is the former case, two results will look similar. ${ }^{6}$

In the third and fourth models, I use different set of cities as a donor pool to address possible problems from other sports team. Washington DC also has football, basketball and hockey team in the all sample period and these teams and games might affect crime as well. This would not create big problem as baseball season is not overlapped with others mostly, but variation in existence of other sports team between cities in a donor pool might be problematic. To deal with this problem, I estimate the original model using a restricted cities which have all 4 major sports team in a donor pool. To do so, cities in the donor pool reduced to $5 .^{7}$ Cities with two MLB teams are also excluded as two teams might have different effect on crime.

In the last model, I use cities that have at least one sports team but don't have MLB team as a donor pool, to address problems which might arise with using cities with treatment effect as a control group. As discussed earlier, I only use cities with baseball team to avoid possible heterogeneity problems. However, heterogeneity among cities without MLB team and Washington DC could be minimized if only cities having at least one sports team are used. Therefore, I use 10 cities as a donor pool in this model. ${ }^{8}$ Note that I did not exploit in-space placebo test for the third and fourth models as the number of cities in a donor pool is too small to construct a test.

Table 1.5 shows only estimated ATE ( $\beta_{8}$ in Equation (1.2)) from the original specification

\footnotetext{
${ }^{6}$ Alternative explanation is possible. Game attendance can be interpreted as general interests on a game in a city, so crime could be committed by people who didn't attend the game but go to a bar or somewhere to watch the game. So bigger attendance might lead more crime which is not related to game attendance. However, as the Nationals' performance was consistently low in all sample period, I argue that the general interests stay same and estimated ATE would capture the direct effect of attendance on crime.

${ }^{7}$ This includes Atlanta, Boston, Denver, Detroit and Philadelphia.

${ }^{8}$ This includes Charlotte, Columbus, Indianapolis, Memphis, Nashville, Oklahoma city, Portland, Sacramento, San Antonio, and San Jose.
} 
and models for robustness check. Model (1) replicates the original results from Table 1.4. Model (2) and (3) use the number of monthly home games and monthly attendance for estimating ATE. Model (4) uses cities with all 4 major sports teams as a donor pool and Model (5) uses cities that don't have MLB teams but have at least one sports team. The results look similar to our main results mostly. For total assault, model (2) and (3) indicate that additional MLB game increases total assault by 1.6, and additional 1,000 monthly attendance increases total assault by 0.05. For simple assault, only model (4) supports the significant effect of MLB games. Model (5) does not report any significant effects. ${ }^{9}$

The main results are generally robust to these alternative specifications. Increased total assaults are more likely to be caused by MLB games, and the restricted sample evidence also supports weak to no evidence between MLB games and crime.

\subsection{Conclusion}

This paper explores the causal relationship between crime and sporting events. Using the case of the Washington Nationals and monthly crime data from the UCR, this paper exploits a natural experiment. From a triple difference-in-difference model and synthetic control approach, this paper finds increases in only assaults by 14 to $15 \%$ monthly or 7 to $7.5 \%$ yearly, after the Nationals moved to DC. These increases in assaults are significant at only the $10 \%$ level, but supported by in-place placebo tests and robustness check. Little to no evidence is found supporting increases in total criminal offenses, larceny and motor vehicle theft.

As the approach in this paper is a single city case study, it is hard to generalize the results to all MLB cities. The results in this paper might reflect some unobservable factors in Washington, DC. At the same time, by applying a synthetic control approach, this paper corrects for unobservable heterogeneity among treatment and control groups as much as possible.

It is hard to determine from the results in this paper whether a local government should

\footnotetext{
${ }^{9}$ Results from Model (5) only provides that weak evidence for assault from the original specification might be also questionable, as other results look similar. This model is most problematic for heterogeneity at the same time.
} 
consider the social cost of increases in crime from a sports franchise when considering a subsidy for new facility construction. Only weak evidence is found for increases in assaults, and it is hard to quantify the size of the social costs from this estimated increase in assaults. While positive, the size of the social costs are difficult to determine.

Additional future research on this topic can be expected, as the existing evidence on the relationship between sport and crime from natural experiments and a regression analysis using high frequency data are conflicting. Quantifying the actual social costs from increased crime attributable to sporting events is also needed. Results from studies on this topic will be very useful for urban policy makers who are interested in attracting a sports team to their region. 


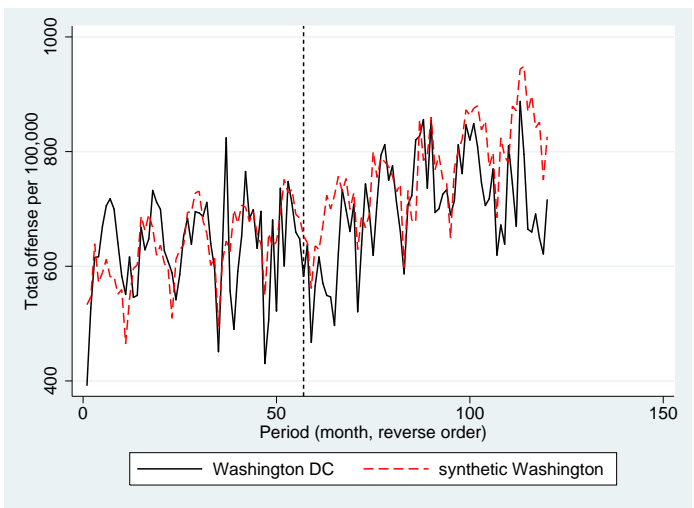

(a) Total offense

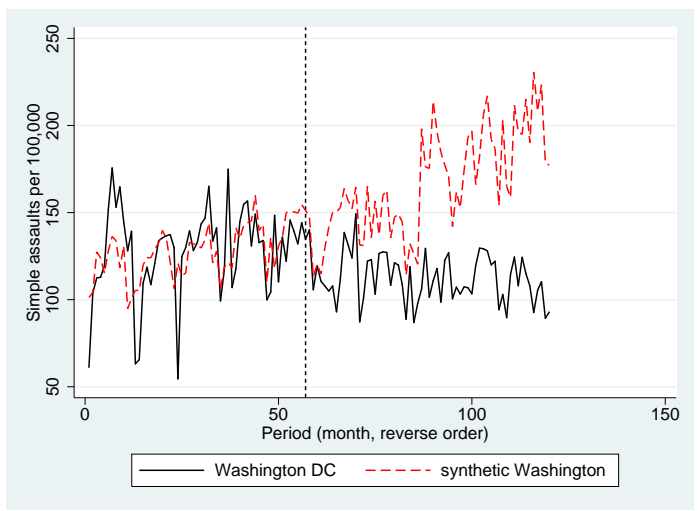

(c) Simple assault

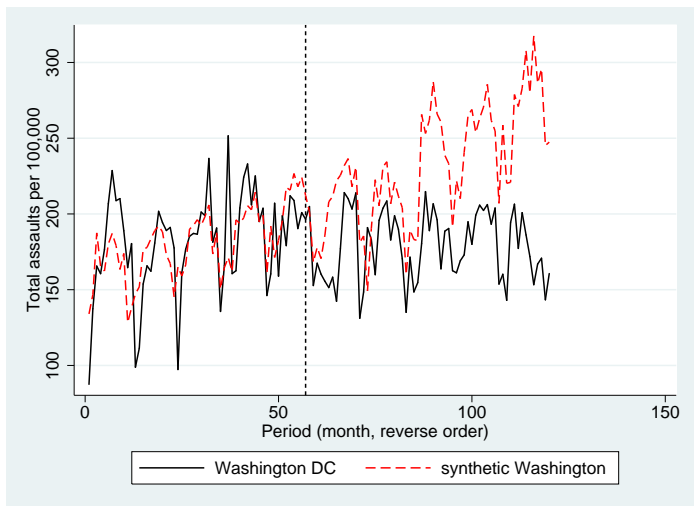

(b) Total assault

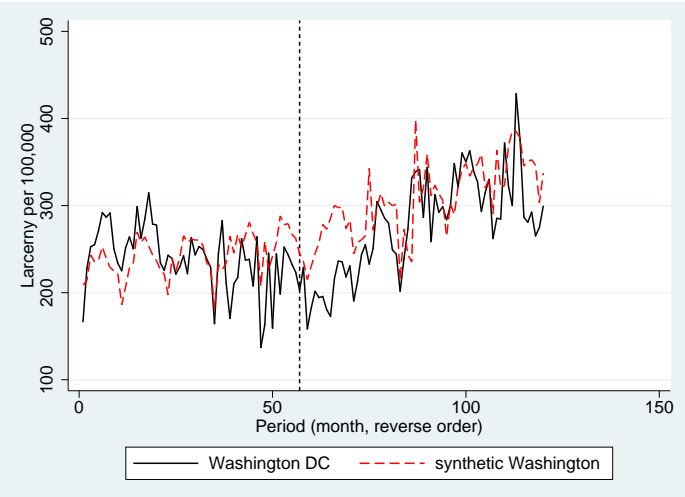

(d) Total larceny

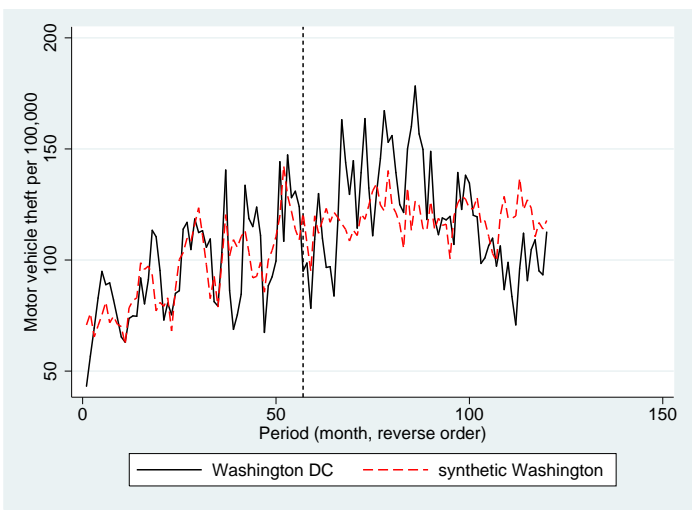

(e) Total motor theft

Note: Vertical dotted line shows the Nationals coming, and right (left) hand side shows pre (post)-intervention period.

Figure 1.1: Changes in Crime: Washington and Synthetic Washington, by Crime Category 


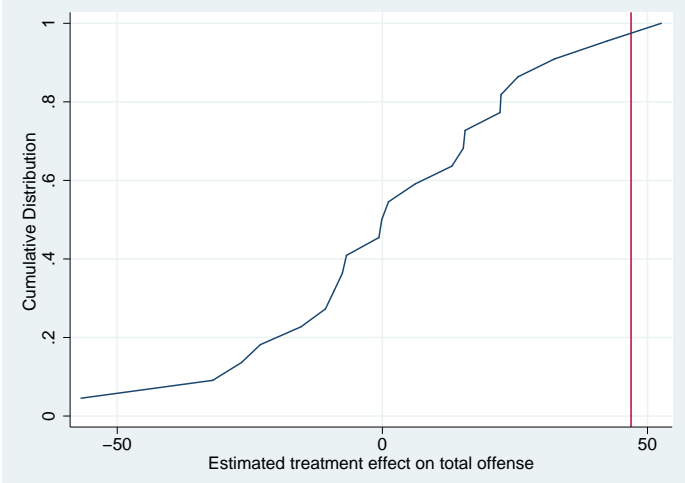

(a) Total offense

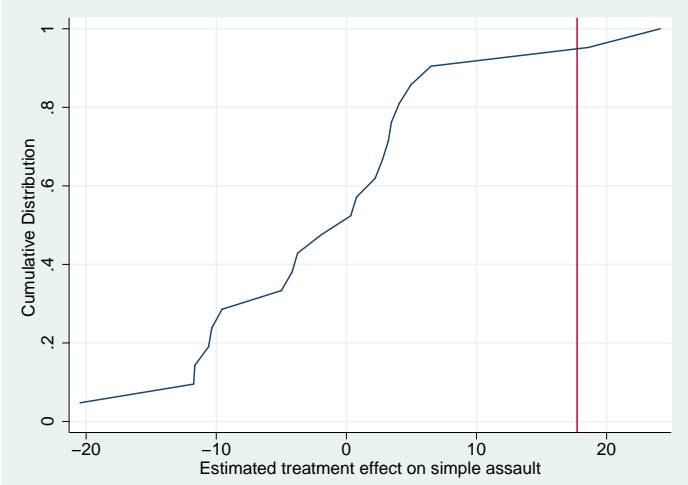

(c) Simple assault

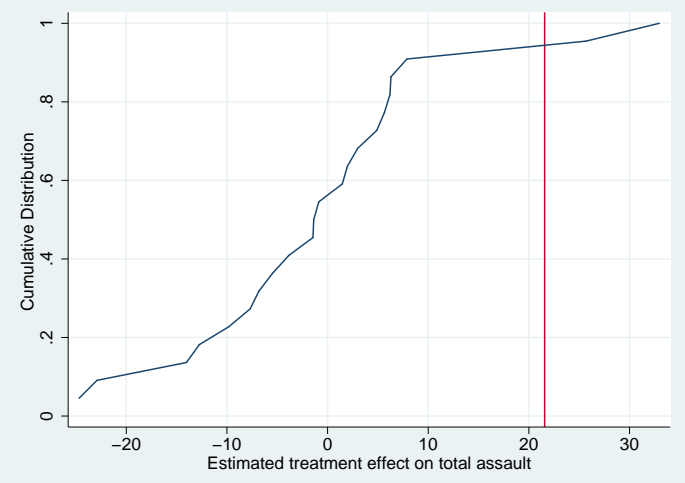

(b) Total assault

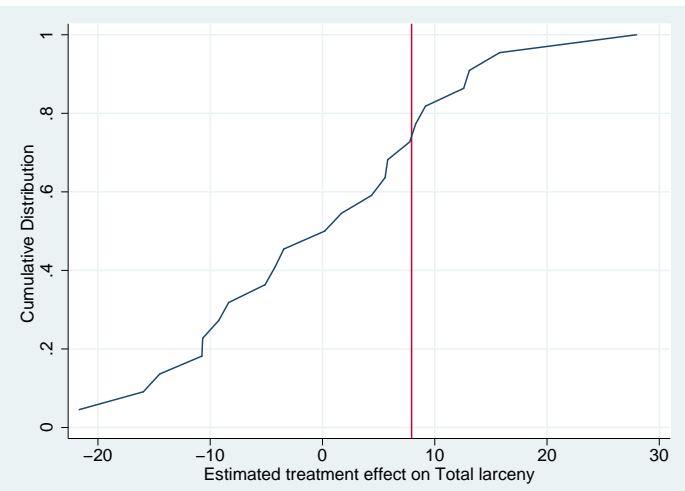

(d) Total larceny

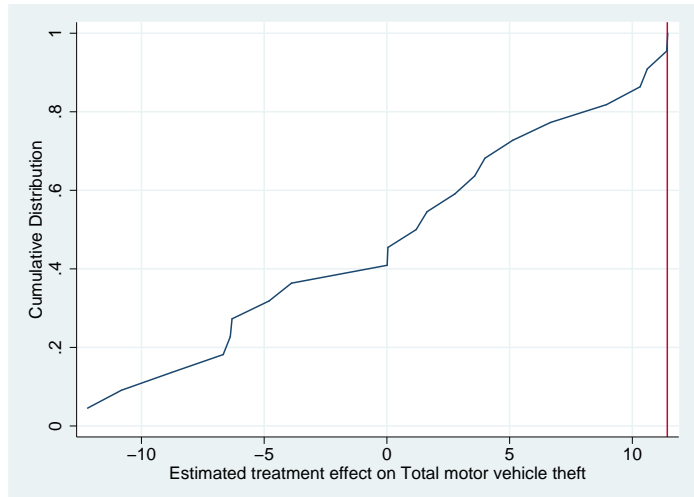

(e) Total motor theft

Note: Vertical line shows the average treatment effect for the Nationals arrival.

Figure 1.2: Cumulative Distribution of Average Treatment Effects, by Crime Category 
Hyunwoong Pyun Chapter 1. MLB and Crime: A Synthetic Control Analysis

Table 1.1: General Characteristics of Sample Cities

\begin{tabular}{|c|c|c|c|c|c|c|c|c|}
\hline & Population & $\begin{array}{r}\text { Age } 18-24 \\
\%\end{array}$ & $\begin{array}{r}\text { Age over } \\
65 \%\end{array}$ & $\begin{array}{r}\text { Black } \\
\%\end{array}$ & $\begin{array}{r}\text { Hispanic } \\
\%\end{array}$ & $\begin{array}{r}\text { College grad } \\
\text { or higher } \%\end{array}$ & $\begin{array}{l}\text { Unemploy- } \\
\text { ment rate }\end{array}$ & $\begin{array}{l}\text { Median } \\
\text { income }\end{array}$ \\
\hline Washington DC & 601,723 & 14.0 & 11.5 & 50.7 & 9.1 & 49.2 & 9.4 & 58,526 \\
\hline Phoenix & $1,445,632$ & 10.3 & 8.0 & 6.5 & 40.8 & 25.5 & 7.4 & 48,823 \\
\hline Los Angeles & $3,792,621$ & 11.1 & 10.2 & 9.6 & 48.5 & 30.2 & 9.1 & 49,138 \\
\hline Anaheim & 336,265 & 10.3 & 9.1 & 2.8 & 52.8 & 23.1 & 9.6 & 57,807 \\
\hline San Diego & $1,307,402$ & 13.2 & 10.6 & 6.7 & 28.8 & 40.8 & 7.3 & 62,480 \\
\hline San Francisco & 805,235 & 9.4 & 13.7 & 6.1 & 15.1 & 51.2 & 7.6 & 78,378 \\
\hline Denver & 600,158 & 10.3 & 10.5 & 10.2 & 31.8 & 40.1 & 7.8 & 45,501 \\
\hline Atlanta & 420,003 & 14.3 & 9.7 & 54.0 & 5.2 & 45.0 & 9.9 & 45,171 \\
\hline Chicago & $2,695,598$ & 11.0 & 10.3 & 32.9 & 28.9 & 34.9 & 11.1 & 46,877 \\
\hline Boston & 617,594 & 19.0 & 10.0 & 24.4 & 17.5 & 42.5 & 9.3 & 50,684 \\
\hline Baltimore & 620,961 & 12.3 & 11.7 & 63.7 & 4.2 & 25.2 & 11.5 & 39,386 \\
\hline Detroit & 713,777 & 10.3 & 11.0 & 82.7 & 6.8 & 11.8 & 24.8 & 28,357 \\
\hline Kansas City & 459,787 & 9.5 & 11.2 & 29.9 & 10.0 & 29.6 & 9.2 & 44,113 \\
\hline St. Louis & 319,294 & 11.8 & 11.4 & 49.2 & 3.5 & 26.9 & 12.7 & 33,652 \\
\hline Cincinnati & 296,943 & 13.9 & 11.1 & 44.8 & 2.8 & 30.8 & 10.7 & 33,681 \\
\hline Cleveland & 396,815 & 10.0 & 12.5 & 55.2 & 10.0 & 13.1 & 17.8 & 27,349 \\
\hline Philadelphia & $1,526,006$ & 12.7 & 12.4 & 43.4 & 12.3 & 22.2 & 12.6 & 36,251 \\
\hline Pittsburgh & 305,704 & 17.3 & 14.6 & 26.1 & 2.3 & 33.8 & 8.6 & 36,019 \\
\hline Arlington & 365,438 & 11.1 & 7.6 & 18.8 & 27.4 & 28.9 & 8.1 & 52,094 \\
\hline Houston & $2,099,451$ & 10.8 & 9.0 & 23.7 & 43.8 & 28.2 & 8.0 & 42,962 \\
\hline Seattle & 608,660 & 11.8 & 10.9 & 7.9 & 6.6 & 55.1 & 6.3 & 60,665 \\
\hline Milwaukee & 594,833 & 13.1 & 9.1 & 40.0 & 17.3 & 21.0 & 11.6 & 35,921 \\
\hline
\end{tabular}

Washington DC is the treatment city, others constitute the donor pool.

Data are from the 2010 U.S. Census. 
Table 1.2: Estimated Weight from Synthetic Control, by Crime Category

\begin{tabular}{lrrrrr}
\hline & $\begin{array}{r}\text { Total } \\
\text { offense }\end{array}$ & $\begin{array}{r}\text { Total } \\
\text { assault }\end{array}$ & $\begin{array}{r}\text { Simple } \\
\text { assault }\end{array}$ & $\begin{array}{r}\text { Total } \\
\text { larceny }\end{array}$ & $\begin{array}{r}\text { Motor vehicle } \\
\text { theft }\end{array}$ \\
\hline Anaheim & 0 & 0 & 0.05 & 0 & 0 \\
San Francisco & 0.317 & 0.135 & 0 & 0.144 & 0.367 \\
Atlanta & 0.238 & 0.244 & 0.10 & 0.05 & 0439 \\
Boston & 0.269 & 0.164 & 0.078 & 0.256 & 0.132 \\
Baltimore & 0.176 & 0.325 & 0.613 & 0.549 & 0.103 \\
Detroit & 0 & 0 & 0 & 0 & 0.056 \\
Pittsburgh & 0 & 0.107 & 0.121 & 0 & 0 \\
Houston & 0 & 0.025 & 0.037 & 0 & 0 \\
Seattle & 0 & 0 & 0 & 0 & 0.138 \\
\hline Citiesthat & & 0 & & 0 & 0
\end{tabular}

Cities that receive positive weight at least once are shown.

Table 1.3: Summary Statistics of Washington and Synthetic Washington

\begin{tabular}{|c|c|c|c|c|c|c|c|c|}
\hline & Population & $\begin{array}{r}\text { Age } 18-24 \\
\%\end{array}$ & $\begin{array}{r}\text { Age over } \\
65 \%\end{array}$ & $\begin{array}{r}\text { Black } \\
\%\end{array}$ & $\begin{array}{r}\text { Hispanic } \\
\%\end{array}$ & $\begin{array}{r}\text { College grad } \\
\text { or higher\% }\end{array}$ & $\begin{array}{l}\text { Unemploy- } \\
\text { ment rate }\end{array}$ & $\begin{array}{l}\text { Median } \\
\text { income }\end{array}$ \\
\hline Washington DC & 601,723 & 14.0 & 11.5 & 50.7 & 9.1 & 49.2 & 9.4 & 58,526 \\
\hline \multicolumn{9}{|l|}{ Synthetic Washington } \\
\hline Total offense & $630,642.1$ & 13.66 & 11.40 & 32.56 & 11.47 & 42.81 & 9.29 & $56,162.46$ \\
\hline Total assault & $599,481.8$ & 13.99 & 11.44 & 42.08 & 8.88 & 37.37 & 9.82 & $47,643.46$ \\
\hline Simple assault & $602,304.8$ & 13.45 & 11.47 & 50.52 & 8.99 & 29.55 & 10.58 & $43,703.13$ \\
\hline Total larceny & $635,965.6$ & 13.68 & 11.44 & 44.79 & 9.22 & 34.33 & 10.28 & $41,452.31$ \\
\hline Motor vehicle theft & $603,869.2$ & 11.93 & 11.40 & 31.66 & 9.11 & 46.81 & 9.39 & $58,554.56$ \\
\hline
\end{tabular}


Table 1.4: Triple Difference-in-Difference Result

\begin{tabular}{lrrrrr}
\hline $\begin{array}{l}\text { Dependent } \\
\text { variable }\end{array}$ & $\begin{array}{r}\text { Total } \\
\text { offense }\end{array}$ & $\begin{array}{r}\text { Total } \\
\text { assault }\end{array}$ & $\begin{array}{r}\text { Simple } \\
\text { assault }\end{array}$ & $\begin{array}{r}\text { Total } \\
\text { larceny }\end{array}$ & $\begin{array}{r}\text { Motor vehicle } \\
\text { theft }\end{array}$ \\
\hline constant & $733.25^{* * *}$ & $213.57^{* * *}$ & $155.79^{* * *}$ & $290.63^{* * *}$ & $117.24^{* * *}$ \\
& $(13.304)$ & $(4.580)$ & $(3.553)$ & $(7.109)$ & $(3.334)$ \\
treat & $-52.767^{* * *}$ & $-44.861^{* * *}$ & $-47.478^{* * *}$ & $-25.065^{* *}$ & 2.399 \\
& $(18.814)$ & $(6.477)$ & $(5.024)$ & $(10.054)$ & $(4.715)$ \\
post & $-127.81^{* * *}$ & $-46.494^{* * *}$ & $-36.969^{* * *}$ & $-60.252^{* * *}$ & -26.157 \\
& $(19.832)$ & $(6.827)$ & $(5.296)$ & $(10.597)$ & $(4.969)$ \\
seas & $71.999^{* * *}$ & $38.844^{* * *}$ & $22.134^{* * *}$ & $32.592^{* * *}$ & 3.390 \\
treat $*$ post & $(19.279)$ & $(6.637)$ & $(5.148)$ & $(10.301)$ & $(4.831)$ \\
treat $*$ seas & 33.414 & $41.493^{* * *}$ & $44.714^{* * *}$ & 20.160 & -7.06 \\
& $(28.047)$ & $(9.655)$ & $(7.490)$ & $(14.987)$ & $(7.028)$ \\
post $*$ seas & -22.677 & $-17.996^{*}$ & $-13.748^{*}$ & -7.764 & -1.356 \\
R-squared & $(27.265)$ & $(9.386)$ & $(7.281)$ & $(14.569)$ & $(6.832)$ \\
treat $*$ post $*$ seas & -16.954 & -11.815 & -4.111 & -8.737 & 4.063 \\
p-value from placebo & $(27.977)$ & $(9.631)$ & $(7.471)$ & $(14.949)$ & $(7.011)$ \\
\hline observation & 52.593 & $25.665^{*}$ & $18.595^{*}$ & 8.296 & 11.444 \\
& $(39.565)$ & $(13.621)$ & $(10.566)$ & $(21.141)$ & $(9.915)$ \\
& 0.000 & 0.046 & 0.048 & 0.273 & 0.000 \\
\hline
\end{tabular}

Standard error in parentheses. ${ }^{*} p<0.1,{ }^{* *} p<0.05,{ }^{* * *} p<0.01$, respectively $\mathrm{p}$-value from placebo shows the p-value from placebo test on $\hat{\beta}_{8}$. 
Table 1.5: Robustness Check

\begin{tabular}{lrrrrr}
\hline $\begin{array}{l}\text { Dependent } \\
\text { variable }\end{array}$ & $\begin{array}{r}\text { Total } \\
\text { offense }\end{array}$ & $\begin{array}{r}\text { Total } \\
\text { assault }\end{array}$ & $\begin{array}{r}\text { Simple } \\
\text { assault }\end{array}$ & $\begin{array}{r}\text { Total } \\
\text { larceny }\end{array}$ & $\begin{array}{r}\text { Motor vehicle } \\
\text { theft }\end{array}$ \\
\hline Model & & & & & $11.444+$ \\
$(1)$ & $52.593+$ & $25.665^{*}+$ & $18.595^{*}+$ & 8.296 & $(9.915)$ \\
& $(39.565)$ & $(13.621)$ & $(10.566)$ & $(21.141)$ & 0.639 \\
$(2)$ & $3.221+$ & $1.624^{*}+$ & $1.106+$ & 0.345 & $(0.682)$ \\
& $(2.722)$ & $(0.937)$ & $(0.727)$ & $(1.453)$ & $0.049^{* *}$ \\
$(3)$ & 0.129 & $0.056^{*}+$ & 0.031 & 0.002 & $(0.023)$ \\
& $(0.093)$ & $(0.032)$ & $(0.25)$ & $(0.049)$ & 11.548 \\
$(4)$ & 44.368 & $18.531^{*}$ & $17.453^{* *}$ & 2.973 & $(10.351)$ \\
& $(37.561)$ & $(10.925)$ & $(7.988)$ & $(19.641)$ & 5.172 \\
$(5)$ & 26.125 & 10.779 & 11.943 & -4.413 & $(10.383)$ \\
\hline
\end{tabular}

Standard error in parentheses. ${ }^{*} p<0.1,{ }^{* *} p<0.05,{ }^{* * *} p<0.01$, respectively + indicates significance at the $10 \%$ level using placebo test.

Placebo test was not conducted in model (4) and (5). 


\section{Chapter 2}

\section{Professional Sporting Events and Traffic: Evidence from US Cities}

\subsection{Introduction}

The presence of a professional sports team in a city can have a substantial impact on local economic activity. Previous research focused primarily on assessing the tangible or intangible benefits of professional sports teams in the local economy; relatively little focused on the direct and indirect costs generated by professional sports teams, facilities, and the games played in these facilities. Because of the large public subsidies provided for the construction and operation of professional sports facilities, a research on costs associated with professional sports is potentially important. A thorough understanding of both benefits and costs of professional sports teams provides and important context for understanding the subsidies provided to professional sports teams.

Most of the existing research on economic costs associated with professional sports focuses on either financial costs associated with facility construction or crime associated with events held in facilities. Pyun and Hall (2016) review the existing evidence on the relationship between professional sporting events and crime. Little research focused on direct costs generated by games like public safety, sanitation, or indirect costs like the opportunity cost of funds used to subsidize the construction and operation of these facilities. In this paper focuses on the relationship between professional sports events and traffic congestion, another 
overlooked cost of hosting sporting events.

Traffic congestion represents a significant problem in many urban areas. Duranton and Turner (2011) note that in 2001, the average American household spent more than 2.5 person-hours each day in a passenger vehicle and investigate the effects of road building and other factors on congestion. Rappaport (2016) extends the standard monocentric city model to include commuting and identifies traffic congestion as a critical factor constraining local growth. Krueger et al. (2009) conclude that commuting to and from work are among urban household's least enjoyable activities, suggesting that additional time spent in a car at the end of the day involves substantial psychic and time costs. Holian and Kahn (2012) investigate the relationship between urban vibrancy, traffic congestion and greenhouse gas emissions; the presence of a professional sports team in a city could represent a type of consumer amenity that contributes to urban vibrancy.

Professional sporting events concentrate large numbers of fans attending games in a small area at the same time. The presence of large surface parking lots and parking structures near sports facilities indicates that large numbers of fans drive to games. Many professional sporting events take place on weekday evenings, and many sports facilities are located in the urban core of large cities. Taken together, this suggests that sporting events could have a substantial impact on traffic congestion.

We empirically analyze the relationship between attendance at Major League Baseball (MLB) games and traffic in US metropolitan areas. MLB represents an ideal setting for assessing the relationship between attendance at sporting events and vehicle traffic. MLB teams typically play 81 home games per season and these games are distributed across all days of the week. Weekday MLB games occur primarily at night, with typical start times of $6 \mathrm{pm}$ to $8 \mathrm{pm}$. This timing means that some fans attending games will be driving to the game during the evening rush hour. In addition, many MLB stadiums are located in the downtown area of cities. The impact of baseball games on traffic is likely larger than the impact of professional football, basketball, or ice hockey because of the long baseball season and relatively large crowds at these games. We analyze traffic data compiled by the Texas A\&M University Transportation Institute that are constructed as part of the 2015 Urban Mobility Scorecard (UMS). The UMS provides annual estimates of traffic and congestion for 
US metropolitan areas. The aggregate annual estimates of vehicle miles traveled and congestion are based on detailed micro data from the Federal Highway Administrations Highway Performance Monitoring System (HPMS) that are highly disaggregated over space (at the level of individual segments of roads) and time (measured at hourly intervals). Note that these data are not directly comparable to aggregate travel data from the Federal Highway Administration's National Household Travel Survey.

We estimate reduced form empirical models explaining variation in vehicle-miles traveled (VMT) for 25 large US metropolitan areas with MLB teams over the period 1990-2014. The empirical models control for MSA population and economic conditions, stadium location, and include MSA and year fixed effects to control for unobservable heterogeneity in factors affecting local VMT. Instrumental variables estimates indicate that each additional 1,000 persons attending an MLB game was associated with 1,700 additional average daily vehiclemile traveled (DVMT) in the host city. For an MLB team drawing 2.8 million fans in a season, this represents an increase of about $0.5 \%$ in DVMT in a metropolitan area. Note that this increase in traffic delay time affects all vehicle occupants in the metropolitan area, not just fans attending MLB games. Fans attending MLB games increase VMT in metropolitan areas. This increase in VMT has implications for traffic congestion, wear and tear on roads, and greenhouse gas emissions that affect the climate.

\subsection{Sports and Traffic}

Fan attendance represents the key link between sporting events and urban traffic. To attend a sporting event, most fans travel between their home or place of work and the venue where the event takes place. Fan attendance at professional sporting events concentrates economic activity spatially in and around facilities and temporally on game day. This concentration has clear economic impacts. Humphreys and Zhou (2015) develop a spatial economic model that includes agglomeration effects stemming from increased fan activity in and around professional sports facilities on game day that predicts the presence of a pro sports team will increase nearby property values and induce other service providing firms to co-locate near the sports facility. Huang and Humphreys (2014) develop evidence of increased 
housing market activity near new sports facilities after they open, supporting the predictions of this model. If this housing market activity reflects in-migration of new residents, the population density near sports facilities will increase. Coates and Humphreys (2003b) show that employees in the amusements and recreation industry - the industry containing athletes and other employees working in sports facility - earn more in cities with professional sports teams than employees in this industry in cities without professional sports teams; these results support the idea of increased economic activity in and near sports facilities. Despite this evidence of increased economic activity near sporting events, no evidence exists supporting the idea that professional sports teams or facilities generate broader economic benefits across metropolitan areas (Coates et al., 2008).

The concentration of fans around sports facilities on game day, and increases in nearby residents year round, has clear consequences for traffic near sports facilities. Most professional sports facilities are located in or near the Central Business District, which also contains many firms employing large numbers of workers who travel to and from their residence on weekdays, often by car. Many fans drive to games and park in dedicated lots surrounding sports facilities or in nearby lots and parking structures that are also used by local workers and residents.

A few papers in the geography literature examined the effect of sports facilities on local parking and traffic. All are case studies and most use surveys of local residents to assess the extent to which increased traffic, parking, crowds, and noise on game days are perceived as a "nuisance" externality by local residents. Humphreys et al. (1983) assessed the importance of negative externalities generated by games played in a football stadium in Southampton, England using household surveys; this paper concluded that traffic and parked cars generated substantially larger "nuisance" externalities on game day than crowds or noise, and the negative effects of traffic and parking extended several miles from the stadium. Chase and Healey (1995) assessed the importance of negative externalities generated by games and rock concerts in a football stadium in Ipswich, England; this paper also concluded that traffic and parked cars were the largest "nuisance" externalities associated with football matches, and found a similarly large traffic impact area. Chase and Healey (1995) discussed proposed stadium location decisions in Australia in light of the existing transportation environment 
around several rugby and Australian Rules Football stadiums located in the center of larger Australian cities and Australian transportation policy initiatives. Although this paper did not develop empirical evidence, the discussion highlights the importance of increased local traffic and parking on game day.

Case-study based evidence clearly indicate that additional traffic around sports facilities on game day represent an important "nuisance" externality to residents of areas near stadiums in England and Australia. The existing theoretical and empirical evidence on the spatial economic of professional sports teams in North America suggests that stadiums and arenas concentrate fans and economic activity in and near sports facilities on game day, and may also increase the number of businesses and residents near sports facilities. All these factors could increase traffic. However, the perceptions of residents near sports facilities about traffic conditions on game day may not reflect outcomes across a metropolitan area, and concentration of fans and economic activity near a sports facility may not increase overall traffic in a metropolitan area. A full understanding of the potential impact of sporting events on traffic in a metropolitan area requires a model of the determination of realized driving outcomes.

\subsection{Determination of Vehicle Miles Traveled}

Duranton and Turner (2011) develop a model of the equilibrium determination of vehicle miles traveled in a city. In this model, a city has road lane miles $R$ and vehicle miles traveled (VMT) on these roads over some specific time period $Q$. Both consumers and businesses demand driving in the city, which depends on the effective price of driving $P$. This effective price of driving includes direct and indirect vehicle operation costs like gas, vehicle maintenance, and insurance, and the time and opportunity cost of driving. The inverse demand curve for VMT, $P(Q)$, slopes down; as the price of driving falls, firms and households drive more miles, other things equal. Other factors unrelated to the price of driving, like business cycle conditions, weather, changes in the price of substitutes or compliments to driving, and increased demand for consumer goods and services that require driving in order to consume, like sporting events, will shift the city's demand curve for 
driving.

The supply curve for driving in a city depends on the roads in the city and the cost of driving. Duranton and Turner (2011) posit a total variable cost function for VMT, $C(R, Q)$ that depends on the existing stock of roads, $R$ and the distance driven by drivers in the city, $Q$. All drivers in the city face the same average cost of driving in equilibrium. Holding lane-miles of road constant in the city, the average cost of driving, $A C(R)$, must increase as VMT increases, thus the supply curve for driving is upward sloping. This result is widely recognized in the transportation economics literature (Small and Verhoef, 2007).

Given demand and supply curves for driving in a city, and a specific quantity of roads, equilibrium VMT in a city is $Q^{*}$, as shown on Figure 2.1. Duranton and Turner (2011) focus on changes in the supply of road-lane miles in a city, which shifts the supply curve for driving to the right as more roads are built, increasing equilibrium VMT in the city. Here, we focus on short run changes in the local economy that shift the demand curve for driving to the right, as shown on Figure 2.1. This shift in the demand curve for driving also increases equilibrium VMT in the city from $Q^{*}$ to $Q^{\prime *}$.

Other models emphasize the importance of residential location choice and commuting to work as an important determinant of urban driving decisions. Albouy and Lue (2015) develop a model of household choice of residence location, and firm choice of location, that makes predictions about length of commute in a standard urban monocentric city model. However, households also drive to shop, consumer entertainment activities, and engage in other non-work related trips. The model developed by Duranton and Turner (2011) is more general, in that total VMT in a city is explained, rather than commuting VMT.

This model of equilibrium determination of VMT provides a useful framework for motivating our empirical work. How might professional sporting events affect equilibrium VMT in a city? Suppose that all fans attending a sporting event drive to the stadium from their residence to watch the game, and these round-trips represent new driving that would not have taken place if the fan did not attend the sporting event. In this case, attending the sporting event increases demand for driving in the city, shifting the demand curve from $D$ to $D^{\prime}$, as shown on Figure 2.1. If these fans live outside the area where the facility is located, then traffic congestion will increase in the area around the facility, and potentially traffic in 
other residential areas of the city.

Alternatively, suppose that all fans drive from their residence to the facility to watch games, but these round-trips to and from the facility replace other trips in the area that would have been taken for other reasons. In this case, total local demand for driving is unchanged, the demand curve for VMT does not shift, and equilibrium VMT, $Q^{*}$ does not change. This case represents "displacement" of VMT within a city. However, traffic congestion near the facility would still increase in this case, since fan travel to the sports facility would not have occurred in that area absent the sporting events.

Another case arises when fans work in the area where the sports facility is located, drive to the area at the beginning of the day and park, walk from their place of employment to the facility, and then drive home after the game ends. To the extent that fans engage in this type of behavior, demand for VMT does not increase, since no new driving takes place despite attendance at the sporting event. As more fans engage in this form of travel to games, the demand curve for VMT shifts less, and equilibrium VMT in the city remains unchanged. This case could be associated with less congestion near the facility, since employees attending the game do not drive home during the evening rush hour, but instead shift their evening drive home to the post-game period.

Another possibility is fans taking some form of public transportation (bus, light rail, train, subway) to games. If public transportation is a substitute for driving, then any fans taking public transportation to games would decrease demand for driving in the city, reducing equilibrium VMT. However, Duranton and Turner (2011) conclude that the presence of public transportation has no effect on equilibrium VMT in cities. Increased use of public transportation by some residents simply encourages additional driving by others. Based on this result, we do not focus on public transportation options in our analysis of the relationship between VMT and sporting events.

This model provides guidance for our empirical analysis. The model shows that our empirical specification must include variables that shift the demand curve for driving and also control for the supply of roads in metropolitan areas. Absent detailed data about how individual fans travel to games, the presence of sporting events could increase VMT, or have no effect on VMT, depending on the type of travel decisions made by individuals attending 
games.

Previous research on the determinants of metropolitan VMT identifies a number of local factors that affect traffic volume. Salon et al. (2012) review the empirical literature on determinants of VMT and show that factors like residential density, land use patterns, road and parking pricing, public transport, and workplace-based programs like telecommuting affect VMT. Road pricing, in the form of 5 to 10 cent per-mile peak-time congestion charges on a small number of roads reduced VMT by $10 \%$ to $15 \%$ in Portland and Sacramento; voluntary employer-based programs to reduce commuting trips reduced VMT by $5 \%$ to $6 \%$ and marketing programs aimed at reducing single-occupance vehicle use reduced VMT by $9 \%$ to $12 \%$.

A substantial literature analyzing the effect of short-run macroeconomic conditions on fatal car crashes exists (Cotti and Tefft, 2011; He, 2016). This literature demonstrates that VMT varies with short-run local macroeconomic conditions. This highlights the importance of controlling for variation in local economic conditions on VMT. If factors like business cycles, congestion pricing on limited local roads, and marketing programs affect VMT, it is certainly possible that attendance at sporting events, especially MLB games which draw large numbers of fans to specific parts of cities on 50 to 60 weeknights per year, could affect VMT in cities.

\subsection{Empirical Analysis}

Following Duranton and Turner (2011), we estimate empirical models of annual VMT in US metropolitan areas. These empirical models include variables reflecting factors that affect demand and supply for driving. Attending professional sporting events is one factor that affects demand for driving in US metropolitan areas. Estimating these models requires data on VMT, road lane-miles, economic and demographic factors that affect demand for driving, and attendance at sporting events. 


\subsubsection{Data Description}

Metropolitan area traffic data come from the 2015 Urban Mobility Scorecard (UMS). ${ }^{1}$ We use total annual hours of delay as a traffic congestion measure, and daily average vehicle-miles traveled (DVMT) as an equilibrium traffic demand and supply measure. The daily vehiclemiles traveled data are constructed by aggregating information from individual roadway sections at an hourly frequency for a large number of roadway segments in metropolitan areas. An individual roadway segment typically contains from 0.5 to 1 miles of roadway. Individual roadway segment DVMT are calculated by multiplying average daily traffic (in terms of vehicle counts) and road miles on each roadway section.

The total annual hours of traffic delay is estimated by comparing the ratio of actual speed to free-flow speed on each roadway section to daily vehicle miles. Lasley et al. (2014) describe the method used to estimate annual hours of traffic delay in metropolitan areas.

Raw micro level data underlying the UMS DVMT data come from the US Department of Highways' Highway Performance Monitoring System (HPMS). Traffic speed data are from INRIX, a company that collects urban traffic data. Annual data on the total road miles in each metropolitan area, a measure of the supply of roadways, come from the HPMS.

Metropolitan area population estimates and unemployment rates in each year come from the US Census Bureau, Bureau of Labor Statistics. Annual MLB team attendance data were collected from daily box scores in baseball-reference.com. We include attendance at postseason and regular season games in the MLB attendance variables.

We construct two stadium location variables to control for stadium location and existing commuting-related traffic congestion. First, we identify stadiums located in the Central Business District (CBD) of each metropolitan area using the CBD definition from the 1982 Census of Retail Trade (Bureau of the Census, 1985). CBDs contain high concentrations of retail and service businesses and "high traffic flow" was one criteria used to identify CBDs. Given this, MLB stadiums located in or near CBDs may experience higher traffic volume for reasons unrelated to games played. The 1982 Census of Retail Trade defined the CBD for each US MSA by listing specific streets which formed the boundary of the CBD. Based on

\footnotetext{
${ }^{1}$ This data set is constructed by the Texas A\&M University Transportation Institute and available at https://mobility.tamu.edu/ums/
} 
this definition, we generate a dummy variable which is equal to 1 for MLB stadiums located in the CBD. For a stadium located outside of the CBD, we measure the driving distance from the nearest boundary of the CBD to the stadium, as many stadiums are located just outside of the CBD; 14 stadiums are located less than 1 mile from the nearest boundary of the CBD. Also, the most recent definition of the CBD, from 1982, is old so there is a chance that the CBD has grown over time and now includes these nearby stadiums. We assume that the distance variable will capture this heterogeneity among stadiums located just outside the 1982 CBD.

The 2015 Urban Mobility Scorecard contains data from 101 metropolitan areas but only 25 are used in our analysis to address possible selection problem which are discussed below. The sample period includes the annual data from 1990 to 2014. Although the raw traffic congestion data are available from 1982, MSA level unemployment rates data are only available after 1990.

Summary statistics are shown on Table 2.1. The total annual hours of traffic delay in metropolitan areas in the sample is 50,876,000 hours, on average. Average DVMT is about 29 million miles with about half those miles driven on freeways and half on arterial streets. The average metropolitan area in the sample has about 5,700 miles of roadway. Large cities usually have higher population density and more traffic, so all traffic measures are larger in large cities. The same argument can be applied to explain the difference in annual traffic delays between cities with and without MLB teams. MLB teams are located in large cities, so all traffic volume and congestion measures are larger in cities with MLB teams. About a quarter of MLB stadiums are located in the CBD, and the average distance from the CBD for the stadiums outside of the CBD is 1.75 miles.

Total metropolitan population varies from around 260,000 (Anchorage, AK, 1990) to over 19 million (New York, 2014). In 1999 Raleigh, NC had the lowest unemployment rate (1.5) while in 1990 McAllen, TX had the highest (22.4). Annual MLB attendance by MSA also varies from around 800,000 (Miami, 2002) to 8,340,000 (New York, 2008). Note that we sum annual MLB attendance across teams if a metropolitan area has more than one MLB team. For example, annual MLB attendance in New York is the sum of attendance for both the Mets and the Yankees. 


\subsubsection{Empirical Model}

Following Duranton and Turner (2011), the basic empirical specification is a reduced form equation for annual traffic outcome measures in metropolitan areas

$$
Y_{i t}=\alpha_{i}+\beta M L B a t t_{i t}+\gamma^{\prime} X_{i t}+\lambda_{t}+u_{i t}
$$

where $Y_{i t}$ is a traffic outcome measure for metropolitan area $i$ in year $t$. We use both average DVMT and annual hours of traffic delay as dependent variables. $\alpha_{i}$ and $\lambda_{t}$ capture metropolitan area fixed effects and year fixed effects, respectively. $X_{i t}$ is a vector of control variables which affect demand and supply for driving in metropolitan areas and vary over time and across metropolitan areas. This vector includes annual MSA population, the MSA unemployment rate, and total road lane-miles in the metropolitan area which reflects the supply of roads in each metropolitan area. Duranton and Turner (2011) demonstrate the importance of controlling for roadway supply when explaining variation in DVMT. $X_{i t}$ also includes the stadium location variables. While many MLB stadiums are located in the city center, either in the CBD or just out of the CBD, some other stadiums are located in the suburbs and this variation in stadium location might systematically affect traffic. To control for this heterogeneity, we include a dummy variable identifying stadiums located in the CBD, and the driving distance from the CBD to the stadium for stadiums located outside the CBD. $u_{i t}$ is a mean zero, possibly heteroscedastic random error term capturing all other factors that affect traffic outcomes in metropolitan areas.

$M L B a t t_{i t}$ reflects annual attendance at MLB games in metropolitan area $i$ in year $t$. We assume this variable potentially shifts demand for driving in the metropolitan area. Note that this attendance data is at the metropolitan area level, so we sum attendance across all MLB teams in metropolitan areas has multiple teams. In this model, $\beta$ captures the effect of attendance at MLB games on traffic congestion in the host city. This is the parameter of interest in this empirical model.

When estimating $\beta$, an endogeneity concern stemming from correlation between MLB attendance and unobservable factors affecting traffic arises from two sources. First, the existence of unobserved heterogeneity in road configuration, weather, or terrain in a metropolitan area with a MLB team might generate biased estimates of $\beta$. To address this problem, we 
limit our sample to the 25 MSAs with MLB teams. ${ }^{2}$ Our empirical results reflect variation in traffic consitions across cities with MLB teams.

Restricting the MSAs in the sample may lead to sample selection problems. To test for selection bias, we performed a variable addition test proposed by Wooldridge (1995). This test procedure is as follows: first, we estimated the effect of the explanatory variables in Equation (2.1) on selection into the sample using a separate Probit model for each year in the sample. The explanatory variables include annual MSA population, unemployment rate, and total road lane-miles. We cannot include the CBD location dummy, distance from the $\mathrm{CBD}$, and the instrument (team winning percentage) because these variables are equal to zero when an MSA does not have a MLB team. For each model, we estimated the inverse Mills ratio (IMR). Next, we included the IMR in the main empirical model, Equation (2.1) and performed a statistical significance test on the parameter estimate on the IMR. This test failed to reject the null hypothesis that the parameter estimate is equal to zero. In this case, the fixed effects-2SLS estimator can address the sample selection bias (Wooldridge, 1995; Semykina and Wooldridge, 2010).

Another endogeneity concern lies in possible unobservable heterogeneity within MSAs with MLB teams when attendance at MLB games is correlated with unobservable factors affecting local traffic conditions. Larger cities tend to have a larger traffic demand and larger stadiums, and may also be associated with unobserved heterogeneity such as the presence of consumption amenities which can affect traffic demand. To deal with this problem, we use the winning percentage for each MLB team in each season as an instrument for MLB attendance. Team winning percentage is highly correlated with attendance, but primarily reflects the quality of the team relative to the rest of the league and random factors occurring on the field. Team success should be uncorrelated with unobservable factors affecting traffic outcomes in a metropolitan area in any year. The first-stage regression associated with Equation (2.1), using winning percentage as an instrument, is

$$
M L B a t t_{i t}=\widetilde{\alpha}+\widetilde{\beta}_{1} w p g 1_{i t}+\widetilde{\beta}_{2} w p g 2_{i t}+\widetilde{\gamma}^{\prime} X_{i t}+\widetilde{\lambda}_{t}+\widetilde{u}_{i t}
$$

\footnotetext{
${ }^{2}$ Our sample contains 25 MSAs because some cities have more than one team. We also have an unbalanced panel, as some cities attracted teams in the sample period.
} 
where $w p g 1_{i t}$ indicates the MLB team's winning percentage in city $i$ in season $t$. Note that we include two winning percentage variables for Chicago, Los Angeles, New York and San Francisco, which all have two MLB teams. The IV estimator, two-stage least squares, uses the predicted value from Equation (2.2) in place of actual attendance in Equation (2.1). If the instrument is valid, the IV results have a causal interpretation; if the parameter estimate of interest is statistically different from zero in the IV model, then attendance at MLB games causes changes in traffic outcomes in metropolitan areas with MLB teams.

\subsubsection{Results}

Table 2.2 contains parameter estimates and other regression diagnostic statistics from Equation (2.1) using both the least squared dummy variable (LSDV) estimator (a two-way fixed effects model including both metropolitan area specific effects and year fixed effects) and the IV estimator using MLB team winning percentage as an instrument, using average daily vehicle-miles traveled on all roads (first two columns) and annual vehicle-hours of delay in a metropolitan area (second two columns) as the dependent variables. Estimated standard errors are cluster-corrected at the MSA level and account for MSA level heteroscedasticity. The results in columns (1) and (3) use the LSDV estimator and results in columns (2) and (4) use the IV estimator.

The LSDV parameter estimates in column (1) generally have the signs predicted by the VMT model above. Larger cities have more DVMT, other things equal. Cities with more miles of roads have more DVMT, which confirms the results reported by Duranton and Turner (2011), the "fundamental law of road congestion." 3 The parameter estimates on the local unemployment rate variable is negative, suggesting that driving demand is cyclical, rising during expansions and falling during recessions; fewer people working in a metropolitan area means fewer people commuting to work, and lower DVMT.

The parameter estimate of interest is on the MLB attendance variable. We expect the sign of this parameter estimate to be positive; more fans in the stands at MLB games means more people driving to the game. This should increase DVMT. The results in columns

\footnotetext{
${ }^{3}$ Duranton and Turner (2011) estimate both LSDV models and IV models that treat total road miles as endogenous.
} 
(1) and (2) confirm this, both parameter estimates are positive and significantly different from zero. The size of this parameter estimate from the LSDV model suggests that each additional 1,000 people attending an MLB game increases DVMT by 1,320 vehicle-miles, on average, holding other factors constant. The average MLB team in the sample drew about 2.8 million fans to games. The parameter estimate on column (1) suggests that this number of fans attending games would increase average DVMT by 3.70 million vehicle-miles. More vehicle-miles traveled in a metropolitan area, holding the number of miles of roads constant, means more congestion on the roads in that metropolitan area. The presence of a MLB team increases traffic congestion in cities, and the more fans that attend games, the worse is the traffic congestion. This applies to all residents of the metropolitan area, not just those who attend MLB games. In this sense, the additional traffic congestion is a negative externality in cities.

The results in columns (2) use the IV estimator, and can be interpreted as causal if the instrument is valid. Table 2.2 reports the standard first-stage (Stock-Yogo) F-statistic for instrument strength. These statistics indicate that our instruments are valid for both models. From column (2), the parameter estimate on MLB attendance in the IV model is positive and statistically different from zero. Fans attending MLB games cause increases in DVMT in metropolitan areas. The increase caused by MLB attendance of 2.8 million, the average attendance in the sample, is $0.5 \%$, bigger than the LSDV results on Column (1).

DVMT is higher in cities with an MLB stadium located in the CBD, relative to cities where the stadium is located in the suburbs. Distance between stadiums nearby and the CBD is not associated with additional DVMT.

While the sample analyzed here contains only metropolitan areas with MLB teams, these results have implications for cities that attract a new MLB team. When a city without one attracts a new MLB team, MLB attendance in that city goes from zero to some positive amount of attendance. Since the IV results on Table 2.2 indicate that higher MLB attendance causes increases in DVMT and traffic congestion, going from zero attendance at MLB games to several million fans attending games would also cause increases in urban traffic. Unfortunately, we lack access to sufficient traffic data to estimate the size of this effect.

The results on Table 2.2 indicate that attendance at MLB games causes increased DVMT, 
but this does not mean that time spent in traffic also increases. The additional miles traveled to and from MLB games could occur at off-peak times, which would not affect time spent in traffic delays much. To assess the effect of MLB games on time spent in traffic delays, we estimate Equation (2.1) using estimated annual metropolitan area vehicle-hours of delay as the dependent variable. This variable is estimated using both DVMT and differences in traffic speed during off-peak "free flow" periods (late evenings and weekends) relative to traffic speed during peak periods on weekdays during the day and early evening. Like the DVMT data, the vehicle-hours of delay estimates are aggregated up from detailed data for specific roadway segments. However, these estimates are noisier than the DVMT estimates because they use data from both the HPMS (VMT) and INRIX (speed). These variables are collected in different ways by different organizations. Because of these problems, the vehicle-hours of delay variable needs to be interpreted with some caution as it may contain substantial measurement error of an unknown form because of matching issues.

The last two columns on Table 2.2 contain LSDV and IV results from Equation (2.1) when the dependent variable is total vehicle-hours of delay in each metropolitan area. The results in column (3), based on the LSDV estimator indicate that attendance at MLB games is associated with additional time spent in traffic delays equal to a $2 \%$ increase in time spent in delays.

The parameter estimates on the metropolitan population variable is positive and statistically different from zero in both models. This indicates that residents of more populous cities spend more time in traffic delays than residents of less populous cites, other things equal. The parameter estimate on the variable reflecting the total road miles in the metropolitan area is not statistically different from zero in either model. Building more roads neither increases or decreases traffic delays in a city. This is consistent with the "fundamental law of road congestion" reported by Duranton and Turner (2011), which shows that building more roads causes more VMT in a metropolitan area, with an elasticity of new road construction of about 1 . If roads increase by $1 \%$ and VMT increases by $1 \%$, traffic delays could be unchanged.

The IV results in columns (4) shows a significant relationship between MLB attendance and traffic delays. The estimated coefficient represents an increase of about $2 \%$ for the 
average metropolitan area with an MLB team in the sample. Note that the cites in this sample also have professional football, basketball, and ice hockey teams that also attract fans to games. The impact of these other sporting events on traffic and congestion is unclear. Most professional football games take place on Sunday afternoons, and professional football teams only play 8-10 home games per season. While attendance at these games is larger than MLB attendance, traffic is lighter on Sunday, so driving to Sunday afternoon football games may not generate the same amount of congestion. Professional basketball and ice hockey games frequently occur on weeknights, but these games draw smaller crowds than baseball (average game attendance is roughly 15,000 to 18,000) and the teams only play about 40 home games per season. The overall impact of these sporting events on traffic and congestion is likely much smaller than the impact of baseball games.

Next, we disaggregate the DVMT data by interstate and arterial road VMT. Interstates are limited access divided highways; arterial roads are commonly called "surface streets". Most of the roads immediately surrounding MLB stadiums are arterial streets, but most MLB stadiums are also located near one or more interstate highways, so the effect of MLB attendance on arterial streets could differ from the effect on interstates. While all interstate road miles contain no stoplights or stop signs, arterial streets have many such traffic restrictions. State departments of transportation maintain all interstates and some arterial streets. Recall that in most cities in the sample, DVMT is about the same on interstates and arterial streets.

Table 2.3 shows results for both the LSDV estimator and the IV estimator when the dependent variable is defined as average DVMT on interstates (first two columns) and arterial roads (second two columns). Columns (1) and (3) use the LSDV estimator; columns (2) and (4) use the IV estimator with annual MLB team winning percentage as the instrument for attendance. The first two columns on Table 2.3 contain evidence that fans attending MLB games increase DVMT on interstates in metropolitan areas. Both LSDV and IV model results support this. The parameter estimates on the unemployment rate variables and the miles of road variables are not generally statistically different from zero in these models.

Last two columns on Table 2.3 shows results for both the LSDV estimator and the IV estimator when the dependent variable is defined as average DVMT on arterial streets. 
Column (3) uses the LSDV estimator and columns (4) use the IV estimator with annual MLB team winning percentage as the instrument for annual MLB attendance.

The results on Table 2.3 indicate that MLB attendance causes increases in total DVMT primarily work through VMT on interstates. The estimated parameters on the total MLB attendance variable are positive and statistically significant for both the LSDV model and the IV model in the first two columns while the estimated parameters are not significant in the last two columns on Table 2.3. This suggests that the increase in DVMT caused by MLB games must be attributable to additional miles driven on interstates. Most fans traveling to and from MLB games travel on interstates, not arterial roads.

The other parameter estimates on Table 2.3 generally have the expected sign and are statistically different from zero. Metropolitan population and the total miles of roads in the metropolitan area are both associated with larger DVMT.

\subsubsection{Robustness Checks}

While we used an IV approach to address potential endogeneity in the MLB attendance variable, it is possible that additional econometric problems exist. One possible problem might come from the unbalanced sample. In this sample period, 5 cities (Denver, Miami, Phoenix, Tampa and Washington DC) either gained a new MLB team or attracted an existing team. This decision might be correlated with other unobserved factors affecting traffic in these cities. To address this problem, we perform a sensitivity test using the subsample which excludes these 5 cities. While we lose observations in this restricted sample, the results from this reduced sample will look similar to the original results if the unbalanced sample does not create any econometric problems.

Another concern arises from metropolitan areas with two teams. In our sample, four metropolitan areas (Chicago, Los Angeles, San Francisco/Oakland, and New York) have two teams throughout the sample period. The existence of two teams might affect a traffic demand in a city differently than a single team. These large metropolitan areas could also have some other unobserved features that have a different impact on traffic. To address this problem, we exclude these 4 metropolitan areas from the restricted sample. This restricted 
sample also helps to determine the extent to which traffic in these four large metropolitan areas drives the results.

Results from these robustness checks are shown in Table 2.4. On this table, only the coefficient estimates of interest, $\hat{\beta}$ (the parameter estimate on the MLB attendance variable) and the estimated standard error on this parameter are shown using the IV estimator. The "Full 25 team MLB MSAs" sample reproduces the original results from Tables 2.2 and 2.3; the "Balanced Sample" represents results using only cities home to an MLB team for the entire period. The "Excluding cities with two teams" sample represents results excluding the four large metropolitan areas with two MLB teams. The results look similar to our main results both qualitatively and quantitatively. One difference is the model using annual vehicle-hours of delay as the dependent variable. The effect of MLB attendance on annual vehicle hours of delay loses statistical significance when excluding the four large metropolitan areas with two teams. This might indicate that the estimated effects on hours of delay are driven by these large metropolitan areas. Also, the parameter estimate for arterial roads VMT becomes statistically significant when excluding these four larger metropolitan areas.

The results reported on Tables 2.2 and 2.3 are generally robust to these sample restrictions. Even when focusing only on metropolitan areas with one MLB team, vehicle-miles traveled in metropolitan areas increases with attendance at MLB games.

\subsection{Conclusions}

This paper examines the extent to which attendance at MLB games increases traffic volume and congestion in host cities. Using traffic volume and congestion data from the 2015 Urban Mobility Scorecard for 25 US cities with MLB teams from 1990 to 2014, we empirically estimate the effect of annual MLB attendance on traffic volume and congestion after controlling for factors that affect demand and supply of driving, economic conditions, and unobservable city and year heterogeneity. Our main results suggest that each additional 1,000 fans attending MLB games increases average daily vehicle-miles traveled by 1,749 miles, which implies a $0.5 \%$ increase in total annual vehicle-miles traveled in a city with annual MLB attendance of 2.8 million, the sample average. This paper also finds a weak evidence of 
an effect of MLB attendance on total annual hours of delay from traffic congestion, although this may be driven by traffic conditions in the four larger metropolitan areas with two MLB teams in the sample.

These results reflect only attendance at MLB games. The cities in the sample also host National Football League, National Basketball Association, and National Hockey League games. Attendance at these games is substantial, and many of the games in these leagues also occur on weeknights. If fans driving to these games have a similar effect on urban traffic, then the overall effect of professional sports on urban VMT and road congestion is larger than the evidence developed here suggests.

Negative congestion externalities are often overlooked when assessing the net local effect of public subsidization of sports facility construction, which is common in the US. Our results suggest that significant increases game-related traffic exist in cities with MLB teams, which leads to substantial social costs. While professional sports may contribute to vibrancy in urban areas, they may not lead to reductions in VMT and greenhouse gas emissions like other factors analyzed by Holian and Kahn (2012). Therefore, urban policymakers contemplating a subsidy for a new professional sports facility, or attracting a team from another city to increase local vibrancy, should take into account this negative consequence.

While this paper is the first to estimate the effect of game attendance on urban traffic volume, we could not quantify this effect in monetary terms. Additional research exploring the social costs created by increased game-related traffic are clearly needed. Also, using aggregated city-level and annual data might obscure the underlying effects of MLB games on traffic volume. It is possible that MLB games create traffic jams in areas around the stadium and reduce traffic in other parts of the city. It is also possible that 81 home games (or around 55 home games on weekdays) are not sufficient to affect outcomes aggregated across a calendar year over entire metropolitan areas. These problems could be addressed by analyzing micro-level data in future research. 


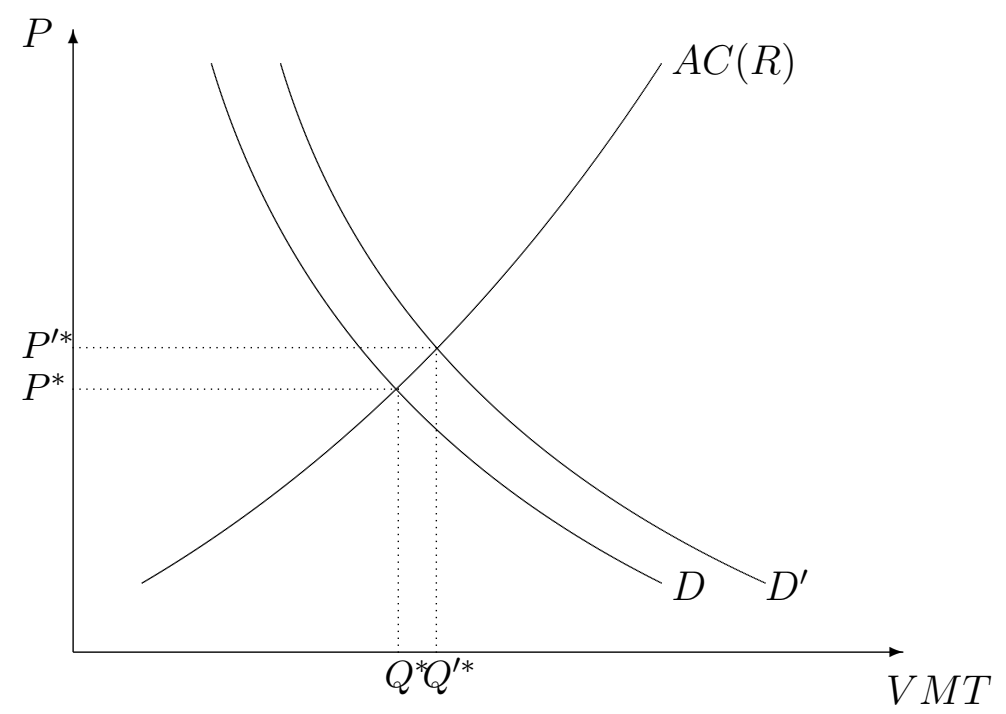

Figure 2.1: Supply, Demand, and Equilibrium VMT 
Table 2.1: Summary Statistics

\begin{tabular}{lrrrrrr}
\hline & \multicolumn{2}{c}{ Full Sample } & \multicolumn{2}{c}{ no MLB team } & \multicolumn{2}{c}{ MLB team in MSA } \\
& Mean & S.D. & Mean & S.D. & Mean & S.D. \\
\hline Average daily vehicle-miles traveled (000) & 29383 & 37907 & 14303 & 9408 & 70728 & 552945 \\
Total annual hours delay (000) & 50876 & 85747 & 21128 & 19142 & 132430 & 132082 \\
Interstate daily vehicle-miles traveled (000) & 14642 & 19648 & 6881 & 5109 & 35919 & 27489 \\
Arterial daily vehicle-miles traveled (000) & 14741 & 18687 & 7421 & 4749 & 34808 & 26378 \\
MSA Population (000) & 2039 & 2613 & 1060 & 676 & 4723 & 3804 \\
MSA unemployment rate & 5.96 & 2.51 & 6.02 & 2.69 & 4.57 & 2.93 \\
MSA total road miles & 5777 & 6249 & 3133 & 1614 & 13028 & 8203 \\
Annual MLB attendance & 755766 & 1443059 & - & - & 2827696 & 1390079 \\
Stadium in CBD & 0.067 & 0.25 & - & - & 0.25 & 0.43 \\
Distance from CBD & 0.47 & 1.57 & - & - & 1.75 & 2.65 \\
\hline Observations & 2200 & & 1612 & & 588 & \multirow{2}{*}{5} \\
\hline
\end{tabular}


Table 2.2: Regression Results, Dependent Variables: Miles Traveled and Delay

\begin{tabular}{|c|c|c|c|c|}
\hline \multirow{3}{*}{$\begin{array}{l}\text { Dependent Variable } \\
\text { Model }\end{array}$} & \multirow{2}{*}{\multicolumn{2}{|c|}{$\begin{array}{c}\text { Average Daily } \\
\text { Vehicle-Miles Traveled }\end{array}$}} & \multirow{2}{*}{\multicolumn{2}{|c|}{$\begin{array}{l}\text { Annual } \\
\text { Vehicle-Hours of Delay }\end{array}$}} \\
\hline & & & & \\
\hline & (1) LSDV & (2) IV & (3) LSDV & (4) IV \\
\hline \multirow[t]{2}{*}{ MLB attendance (000) } & $1.322^{*}$ & $1.749^{* *}$ & $10.74^{* *}$ & $9.913^{* *}$ \\
\hline & $(0.753)$ & $(0.818)$ & $(4.254)$ & $(3.910)$ \\
\hline \multirow[t]{2}{*}{ Population (000) } & $15.26^{* * *}$ & $15.18^{* * *}$ & $62.85^{* * *}$ & $63.01^{* * *}$ \\
\hline & $(2.791)$ & $(2.607)$ & $(18.11)$ & $(17.56)$ \\
\hline \multirow[t]{2}{*}{ Unemployment rates } & -882.1 & $-870.2^{*}$ & $-5212^{* *}$ & $-5235^{* *}$ \\
\hline & $(570.085)$ & $(527.531)$ & $(2252)$ & $(2188)$ \\
\hline \multirow[t]{2}{*}{ Total road miles } & $0.843^{* *}$ & $0.855^{* *}$ & 0.601 & 0.578 \\
\hline & $(0.393)$ & $(0.374)$ & $(1.574)$ & $(1.490)$ \\
\hline \multirow[t]{2}{*}{ Stadium in CBD } & $2951^{* * *}$ & $3017^{* * *}$ & 4033 & 3904 \\
\hline & $(926.6)$ & $(873.1)$ & (7299) & $(6821)$ \\
\hline \multirow[t]{2}{*}{ Distance from CBD } & 434.8 & 459.1 & 3441 & 3394 \\
\hline & $(364.7)$ & $(355.2)$ & $(2194)$ & $(2079)$ \\
\hline City \& year fixed effects & $\mathrm{Y}$ & $\mathrm{Y}$ & $\mathrm{Y}$ & Y \\
\hline Instrument & & $\mathrm{B}$ Win $\%$ & & MLB Win \% \\
\hline First stage F statistic & & 79.8 & & 79.8 \\
\hline Number of cities & 25 & 25 & 25 & 25 \\
\hline Years & 25 & 25 & 25 & 25 \\
\hline
\end{tabular}

$* p<0.10, * * p<0.05, * * * p<0.01$

Cluster-corrected standard errors at MSA level in parentheses. 
Table 2.3: Regression Results, Dependent Variable: Interstate and Arterial Miles Traveled

\begin{tabular}{|c|c|c|c|c|}
\hline \multirow{2}{*}{$\begin{array}{l}\text { Dependent Variable } \\
\text { Model }\end{array}$} & \multicolumn{2}{|c|}{$\begin{array}{c}\text { Daily Interstate } \\
\text { Vehicle-Miles Traveled }\end{array}$} & \multicolumn{2}{|c|}{$\begin{array}{c}\text { Daily Arterial Road } \\
\text { Vehicle-Miles Traveled }\end{array}$} \\
\hline & (1) LSDV & (2) IV & (3) LSDV & (4) IV \\
\hline \multirow[t]{2}{*}{ MLB attendance (000) } & $0.811^{* *}$ & $0.883^{* *}$ & 0.511 & 0.866 \\
\hline & $(0.314)$ & $(0.350)$ & $(0.492)$ & $(0.563)$ \\
\hline \multirow[t]{2}{*}{ Population (000) } & $8.612^{* * *}$ & $8.598^{* * *}$ & $6.653^{* * *}$ & $6.586^{* * *}$ \\
\hline & $(0.775)$ & $(0.746)$ & $(2.227)$ & $(2.060)$ \\
\hline \multirow[t]{2}{*}{ Unemployment rates } & $-445.9^{*}$ & $-443.9^{*}$ & -436.1 & -426.3 \\
\hline & $(254.2)$ & $(239.0)$ & $(350.7)$ & $(320.5)$ \\
\hline \multirow[t]{2}{*}{ Total road miles } & 0.145 & 0.147 & $0.699 * *$ & $0.708^{* * *}$ \\
\hline & $(0.147)$ & $(0.137)$ & $(0.286)$ & $(0.275)$ \\
\hline \multirow[t]{2}{*}{ Stadiums in CBD } & 1227 & 1239 & $1723^{*}$ & $1778^{* *}$ \\
\hline & $(903.0)$ & $(870.2)$ & $(892.4)$ & $(756.9)$ \\
\hline \multirow[t]{2}{*}{ Distance from CBD } & 246.5 & 250.6 & 188.3 & 208.5 \\
\hline & $(204.8)$ & $(197.1)$ & $(228.7)$ & $(221.8)$ \\
\hline City \& year fixed effects & $\mathrm{Y}$ & $\mathrm{Y}$ & $\mathrm{Y}$ & Y \\
\hline Instrument & & $\mathrm{B}$ Win $\%$ & & MLB Win \% \\
\hline First stage F statistic & & 79.8 & & 79.8 \\
\hline Number of cities & 25 & 25 & 25 & 25 \\
\hline Years & 25 & 25 & 25 & 25 \\
\hline
\end{tabular}

$* p<0.10, * * p<0.05, * * * p<0.01$

Cluster-corrected standard errors at MSA level in parentheses. 
Table 2.4: Robustness Checks - IV Estimator

\begin{tabular}{|c|c|c|}
\hline Dependent Variable & Sample & $\hat{\beta} /$ s. e. \\
\hline \multirow[t]{6}{*}{ Average Daily Vehicle-Miles Traveled } & Full 25 MLB MSAs & $1.749^{* *}$ \\
\hline & & $(0.818)$ \\
\hline & Balanced Sample & $1.867^{* *}$ \\
\hline & & $(0.792)$ \\
\hline & Excluding cities with two teams & $1.947^{* * *}$ \\
\hline & & $(0.696)$ \\
\hline \multirow[t]{6}{*}{ Annual vehicle-hours of delay } & Full 25 MLB MSAs & $9.913^{* *}$ \\
\hline & & $(3.910)$ \\
\hline & Balanced Sample & $10.16^{* * *}$ \\
\hline & & $(3.712)$ \\
\hline & Excluding cities with two teams & 1.886 \\
\hline & & $(1.565)$ \\
\hline \multirow[t]{6}{*}{ Daily Interstate Vehicle-Miles Traveled } & Full 25 MLB MSAs & $0.883^{* *}$ \\
\hline & & $(0.350)$ \\
\hline & Balanced Sample & $1.001^{* * *}$ \\
\hline & & $(0.326)$ \\
\hline & Excluding cities with two teams & $1.069^{* * *}$ \\
\hline & & $(0.340)$ \\
\hline \multirow[t]{6}{*}{ Daily Arterial Road Vehicle-Miles Traveled } & Full 25 MLB MSAs & 0.866 \\
\hline & & $(0.563)$ \\
\hline & Balanced Sample & 0.866 \\
\hline & & $(0.554)$ \\
\hline & Excluding cities with two teams & $0.877^{* *}$ \\
\hline & & $(0.442)$ \\
\hline
\end{tabular}

$* p<0.10, * * p<0.05, * * * p<0.01$

Cluster-corrected standard errors at MSA level in parentheses. 


\section{Chapter 3}

\section{The Effect of Smoking Cessation on Health Outcomes: Evidence from the British Household Panel Survey}

\subsection{Introduction}

Cigarette smoking affects health. Among the 7,000 chemicals in tobacco smoke, at least 250 are known to be harmful and can cause cancer or other diseases (U.S. Department of Health and Human Services, 2014). However, empirical analysis of the effect of smoking faces several empirical challenges including self-selection bias and reverse-causation. Smoking and smoking cessation cannot be assigned randomly to individuals, so empirical research on the impact of smoking and smoking cessation must use observational, non-experimental data. In this case, the estimated effect of smoking or smoking cessation can be biased when smokers undertake more other unhealthy behaviors than non-smokers or when survey participants systematically differ from the general population. Empirical analysis of smoking cessation and health outcomes can suffer from reverse causality if quitters stop smoking because of some unobserved smoking-related health problems.

In health economics, a number of papers address the self-selection problem in the context of smoking behavior. For example, Contoyannis and Jones (2004) and Balia and Jones (2008) apply a recursive multivariate probit model to address the self-selection problem and find a 
negative impact of smoking on self-reported health and mortality rates ${ }^{1}$. Adda and Lechene (2013) showed the existence of health selection effects in smoking decisions and found that the effects of smoking varied systematically with smoking intensity. However, the estimated effects of smoking on health outcomes are mostly driven by observed differences between current smokers and non-smokers while government smoking policy interventions policies tend to concentrate on smoking cessation. The impact of smoking cessation programs on health outcomes should be shown in observed variation between current smokers and former smokers. The paper compares health outcomes of current smokers with former smokers after quitting.

In 2016, the Office on Smoking and Health at the Centers for Disease Control and Prevention spent $\$ 70$ million on the National Tobacco Control program and the Quitline program ${ }^{2}$. These programs aim to prevent initiation of tobacco use especially among youth and young adults, and to promote cessation and assist tobacco users to quit. Evaluation of these programs requires information about the effect of smoking cessation on health outcomes. The estimated effect of smoking cessation on health outcomes would likely be smaller than the effect of current smoking on health outcomes, as quitters smoked prior to cessation, and past smoking behavior already affected their health negatively. No recent studies try to estimate this effect despite the existence of new techniques to deal with self-selection.

This paper estimates the impact of smoking cessation on health outcomes. Using the most recent 10 years of data from the British Household Panel Survey (BHPS), this paper explores the short-term and long-term effects of smoking cessation. To focus on the impact of smoking cessation, I define quitting behavior as the treatment in the empirical analysis and address self-selection by applying a propensity score matching technique. The results show a positive impact of smoking cessation on self-reported health after controlling for smoking intensity, in terms of number of cigarette smoked or smoking tenure (i.e., the number of years an individual reported smoking); at the average smoking intensity, quitters were $6 \%$ to $8 \%$ more likely to report positive health outcomes than inconsistent smokers. These results

\footnotetext{
${ }^{1}$ Bhattacharya et al. (2006) provide evidence that a multivariate (bivariate) probit model is preferred to an instrumental variable approach with multiple binary dependent variables.

${ }^{2}$ Source: https://www.cdc.gov/tobacco/about/osh/program-funding/index.htm
} 
are useful for evaluating the effectiveness of smoking cessation programs.

\subsection{Literature Review}

Most research on smoking cessation comes from clinical or epidemiological fields. Early studies in these areas mostly reported positive effects of smoking cessation on health outcomes like mortality. Epidemiological mortality studies found decreases in mortality rates among former smokers 10\% to 30\% lower than current smokers (Doll and Peto, 1976; Hammond, 1966; Kahn, 1966; Carstensen et al., 1987)³. These studies analyzed both short-term and long-term health impacts of smoking cessation and found that the impact on health increased with the duration of smoking cessation. Also, some studies found a differential effect of smoking cessation by smoking intensity (Hammond, 1966; Kahn, 1966; Carstensen et al., 1987).

Other studies used the number of hospitalized days as the health outcome, or the number of physician visits and the number of hospitalized days. The estimated effect of smoking cessation on these health outcomes was varied. Ashford (1973) reported no consistent impact of smoking cessation on physician visits, Oakes et al. (1974) found that former smokers had more physician visits than current smokers, and Vogt and Schweitzer (1985) found that former smokers had fewer physician visits after controlling for age, gender, and alcohol use. Other papers looked at survey data and mostly focused on informal health outcome measures, like self-reported health status or absence from work. These studies consistently found a positive effect of smoking cessation (Balarajan et al., 1985; Segovia et al., 1989).

Previous findings discussed above were estimated using data with some limitations: the studies were constructed with either too specific a sample (e.g., UK doctors only; Doll and Peto (1976), a single city case study; Ashford (1973), small sample size (e.g., less than 3,000 participants; Segovia et al. (1989); Oakes et al. (1974); Vogt and Schweitzer (1985)), or crosssectional data only (Ashford, 1973; Oakes et al., 1974; Vogt and Schweitzer, 1985; Balarajan et al., 1985; Segovia et al., 1989). Studies with a mortality follow-up relied on a one (or two) time survey question on smoking status and socio-economic status (Doll and Peto, 1976;

\footnotetext{
${ }^{3}$ Doll et al. (2004) update the results with 50 years' mortality follow-up.
} 
Kahn, 1966; Carstensen et al., 1987). Hammond (1966) used panel data observed only 4 times at annual intervals.

The US Surgeon General Report regularly summarizes existing research on the health consequences of smoking; the 1990 report focused on research on smoking cessation. This report described six possible problems in the empirical literature on smoking cessation: 1) self-reported former smokers are actually smoking, 2) former smokers tend to have smoked less than persistent smokers, 3) smoking practices and the presence of smoking-related diseases affect participation in studies, 4) small numbers of subjects in studies, 5) former smokers tend to lead a healthier lifestyle than persistent smokers, and 6) current smokers developing symptoms of disease quit smoking (U.S. Department of Health and Human Services, 1990). The studies discussed above did not address these problems.

There are some recent studies on smoking cessation in medical fields. For example, Jha et al. (2013) estimate hazards of smoking and benefits of cessation using US National Health Interview Survey data. While they defined smoking status carefully and controlled for socioeconomic characteristics and drinking behavior, they failed to address the problems listed in the Surgeon General Report.

This paper address the empirical issues identified in the U.S. Department of Health and Human Services (1990) by applying propensity score matching. Among the listed problems, I focus on the issues from self-selection and reverse causation. Reverse causation would generate overestimated effects of quitting if the estimated effects of quitting capture changes in health reflecting contemporaneous poor health status (for example when a former smoker quit smoking because her health status deteriorated prior to quitting). Stratification on the propensity score from a sample of inconsistent smokers can address the reverse causality effect of poor health on quitting. Also, the number of cigarettes smoked and smoking tenure is controlled for through the matching technique. The effect of other health-related behaviors are controlled for in the matching technique. The British Household Panel Survey contains a relatively large number of nationally representative individuals and more frequent observations as the same smoking-related questions were asked in every wave of the survey. 


\subsection{Data}

The data analyzed in this paper come from the British Household Panel Survey (BHPS). The BHPS contains an annual longitudinal survey of approximately 4,000 to 10,000 individuals for 18 waves (years) from 1991 to 2008. Data from the most recent 10 waves (1999-2008) are analyzed in this paper as questions regarding health-related behaviors such as participation in physical activity and drinking only appear in recent waves. The sample contains only individuals who appear in all 10 waves.

Each wave contains a question asking about current smoking status and the number of cigarettes smoked per day for smokers. From this question, I define all time smokers as those individuals who report themselves as smoking in all 10 waves and quitters as those who report smoking in earlier waves, quit at some point, and report not smoking for at least 5 consecutive waves. I also define all time non-smokers as those individuals who report themselves as not smoking in all 10 waves and inconsistent smokers as those individuals who report themselves as smoking in some waves but not smoking in other waves. Others include individuals who did not report their smoking status for all waves; they are dropped in this paper. Table 3.1 shows the frequency distribution for the various smoking groups.

This paper focuses on the inconsistent smoker and quitter groups only to correct for selfselection and reserve causation problems. Excluding the largest portion of individuals might be problematic as members of the remaining groups could be systematically different from the rest of the sample. But smoking or quitting cannot be assigned randomly, as mentioned earlier. Given this limitation, this paper addresses the problem of self-selection into the quitting group using propensity score matching. More discussion of the matching method will follow.

The BHPS also contains a question about each individual's health status. This question asks about self-reported overall health over last 12 months using 5 possible responses: excellent, good, fair, poor, and very poor. Following Contoyannis and Jones (2004) and Balia and Jones (2008), I create a dummy variable for self-reported health which is equal to 1 when an individual reports his/her health as excellent and good, and 0 otherwise.

The propensity score matching uses variables capturing socio-economic status from the 
BHPS as covariates. These variables include age, annual income, gender, marital status, number of children, higher education, self-employment, retirement status, dummy variables for geographical residence, and a social class classification variable. ${ }^{4}$

Variables reflecting health-related behaviors are also included in the BHPS. The survey contains questions asking about participation in physical activity and drinking. The questions ask whether an individual participates in physical activity (e.g., walking or swimming) or goes for a drink at a pub or club with following categories: at least once a week, once a month, several times a year, once a year or less, and never. I define a dummy variable which equals 1 when an individual participates in physical activity (goes out for a drink) at least once a week, and 0 otherwise. These questions are only asked once every two years. I assume that individuals maintain their behavior over a two year period.

The BHPS also contains questions regarding smoking intensity. The number of cigarettes smoked is recorded in every wave. Wave 9 contained a question asking the age when an individual first started to smoke cigarettes regularly. Using this first smoking age and current age, smoking tenure (the number of continuous years of smoking) is calculated.

\subsection{Empirical Methods}

\subsubsection{Definition of Treatment and Control Groups}

To concentrate on the effect of smoking cessation, I define the treatment group as quitters and inconsistent smokers as the control group. The ideal control group would be all time smokers as they did not experience any changes in their smoking behavior in all 10 waves. However, reverse causality can not be addressed with the all time smoker group as quitters are systematically different from all time smokers. I found evidence that quitters are likely to report their health status as fair and poor when they quit smoking compared to all time smokers. The fair/poor health reports by quitters also exist over the first two years of smoking cessation. This reverse causation is not addressed with the propensity score matching on the all time smoker group and the estimated effect of smoking cessation would

\footnotetext{
${ }^{4}$ Following Contoyannis and Jones (2004); Balia and Jones (2008), the social class classification is derived from the Registrar Generals Social Class (RGSC), which is based on reported occupation.
} 
be overstated as a result. On the other hand, inconsistent smokers are individuals who stopped smoking at some point but failed to quit permanently. In this case, inconsistent smokers can resemble the quitter group better than all time smokers as their motivation to stop smoking would be similar to the quitters' motivation. Propensity score matching with stratification is applied to the sample of inconsistent smokers to deal with remaining problems from self-selection and reverse causation. Details on this approach are discussed in the next section.

Among inconsistent smokers, focusing on a group of individuals who attempted to stop smoking at the same time with quitters but could not quit successfully would generate an interesting control group. Note that quitters are the group of individuals who started to quit smoking in the first 5 waves following the group definition and the whole inconsistent smokers includes many individuals who stopped smoking in the later waves. This subgroup of whole inconsitent smoker includes individuals who stopped smoking in this first 5 waves with quitters, but started to smoke again in the later waves. Intuitively, this group of individuals are likely to be very similar to quitters except for their success in smoking cessation, as they made the decision to quit at the same time. This group of individuals may have stopped smoking because they develop a health problem, like individuals in the former smokers group. Therefore, I use this group of individuals as a second control group. Since the size of this group is smaller than the whole sample of inconsistent smokers and close to the size of the quitter group, propensity score matching is not applied to this group. I will call the first control group "whole inconsistent smokers" and the second control group with individuals who tried to quit smoking but failed as the "failure group."

\subsubsection{Propensity Score Matching}

Before estimating the treatment effect of smoking cessation, propensity score matching is employed to construct an appropriate control group from the sample of inconsistent smokers. The matching technique assumes that outcomes are independent of group participation (quitting) conditional on a set of observed variables. I select variables which are likely to determine the probability of quitting, which include age, income, gender, marital status, the 
number of children, education, self-employed status, retirement status, social class classification, dummy variables for resident location, the number of cigarettes smoked per day, and smoking tenure. Following Gaynor et al. (2012), I use the three closest matches for each quitter with replacement. As quitters stop smoking in various waves, matching is performed separately using observations for quitters and smokers from the same wave. As quitters are as defined those who quit smoking for at least 5 years, the decision to quit was made in the first five waves. Therefore, five separate matching procedures were performed. When matching, I use data from the wave when the treated individual actually quit smoking. Propensity score matching usually employs data from before the assignment of any treatment. Matching on data from different waves might be problematic, but the BHPS asks about current smoking status and other covariates based on the past full year, so I assume that the quitting decision was made after the covariates used in matching were determined.

This matching method is also required to address any possible reverse causality. Quitters tend to report worse health in the year when they quit smoking. Using data from waves before the quitting decision was made would not completely address this problem.

To address reverse causality, I stratify the sample according to self-reported health in the quitting group following Lechner (2009). Generally, for an individual who reported his/her health status as excellent or good (fair or poor) and reported she quit smoking in a specific wave, I applied the matching method to the group of inconsistent smokers who reported their health status as excellent or good (fair or poor) in the same wave. This method ensures that differences in covariates are not affected by health status, which can generate reverse causality in this setting.

Table 3.2 shows summary statistics for variables used in matching from the 2000 wave. The first column shows averages for the quitter (treatment) group, the next two columns show averages for the whole inconsistent smokers control group before and after matching. Stars indicate p-values from a t-test of differences in means between the treatment and control groups. As shown, several statistically significant differences between the groups exist before matching. But these differences do not exist after matching, except in the case of the number of cigarettes smoked. Note that actual matching is performed using data from 5 different waves separately; this table only shows approximate results from one waves 
matching. The last column shows averages for the failure control group. Since propensity score matching is not performed for this group due to the small size, several variables report a statistically significant difference across groups. However, this group represents the quitter group well intuitively and shows a more similar pre-trend in self-reported health, as shown in Figure 3.1.

Figure 3.1 shows the trends in pre- and post-treatment (smoking cessation) health outcomes for quitters and smokers. The vertical red line represents the timing of the decision to quit. As shown in the figure, both control groups closely resemble the pre-trend of health status for quitters. While the whole inconsistent smokers group shows marginally worse health reports for some pre-quitting periods, the failure group exhibits a similar time trend to quitters, which supports the idea that the failure group resembles the quitter group. Also, reverse causation is addressed in this context, as no large difference exists in health status at the red (quitting) line. Note that these figures only show unconditional means by quitting year. Assessing the treatment effect would require conditioning on time fixed effects, as the quitting decision was made in different years, as well as controlling for heterogeneous effects by smoking intensity.

\subsubsection{Difference-in-Differences Model}

After applying propensity score matching, a difference-in-difference approach is used to estimate the treatment effect:

health $_{i t}=\beta_{0}+\beta_{1}$ treat $_{i}+\beta_{2}$ quit $_{i t}+\beta_{3}$ quit $_{i t} * \#$ cigarette $_{i}+\beta_{4}$ quit $_{i t} *$ smokingtenure $_{i}+\lambda_{t}+u_{i t}$

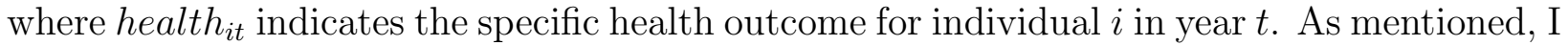
use self-reported health status as the relevant health outcome. treat $_{i}$ equals 1 if an individual $i$ is in the quitter (treatment) group for all waves. $\lambda_{t}$ captures year-fixed effects, $u_{i t}$ is an unobservable error term reflecting other unobservable factors that influence health. quit $t_{i t}$ is the variable of interest, which equals 1 if an individual $i$ stops smoking in wave $t$, and further subsequent waves. In this specification, $\beta_{2}$ captures the treatment effect of quitting. 
Positive estimates of $\beta_{2}$ indicate a positive impact of smoking cessation on health outcomes. Individual fixed effects are not included in the regression model as heterogeneity among individuals is already controlled through propensity score matching.

Smoking intensity and smoking tenure (i.e., the number of continuous years an individual reported smoking) generate heterogenous effects of smoking cessation on health. For example, Adda and Cornaglia (2006) report differences in the health effects of increased smoking intensity generated by cigarette tax increases. To control for smoking intensity, the number of cigarettes smoked per day and smoking tenure are included in the empirical model. quit $_{i t} * \#$ cigarette $_{i}$ and quit ${ }_{i t} *$ smokingtenure $_{i}$ indicates the interaction terms between quit $t_{i t}$ and the number of cigarettes smoked before quitting and smoking tenure. $\beta_{3}$ and $\beta_{4}$ captures the heterogenous effect of quitting according to smoking intensity. I expect $\beta_{3}$ and $\beta_{4}$ be negative.

\subsection{Results}

Table 3.3 shows the results from Equation (3.1) for the two different control groups. The first column shows results for the whole inconsistent smokers control group, and the last column shows results for the failure control group. The estimated coefficients on the treated group is not statistically different from zero for both control groups. This result indicates that there are no differences between the control group and treatment group except for quitting behavior, which supports the idea that the two control groups represent the quitter group in pre-quitting periods reasonably well.

The estimated treatment effects are positive and statistically significant after controlling for smoking intensity and tenure. For example, the probability that an individual reports their health as excellent or good after quitting increases by 27 to 28 percentage points. However, these effects are reduced by prior smoking intensity and tenure. Each additional cigarette smoked per day before quitting decreases this impact by 0.8 percentage points. The average number of cigarettes smoked for each quitter was 9.6, which generates a 7.7 percentage point decrease in the treatment effect. Smoking tenure also decreases the estimated treatment effect by 0.5 percentage points. At the average smoking tenure for quitters 
(26.83 years), the estimated treatment effects will be reduced by 13.4 percentage points. As a result, the probability of reporting good or excellent health for the average quitter is 5 to 6 percentage points higher after quitting. Based on the average self-reported health for quitters before quitting (74.9\%), the estimated effects represents an $8 \%$ increase in the likelihood of improved self-reported health outcomes.

\subsection{Robustness Checks}

Several alternative specifications are estimated to confirm that the estimated treatment effects are driven by smoking behavior. The BHPS contains questions asking about individual's specific health problems. Among these questions, I choose one question asking whether an individual has problems with chest/breathing, asthma, or bronchitis. Respiratory problems are closely related to smoking behavior and the estimated effect on this problem should show up clearly if variation in smoking is well identified. Therefore, I estimate Equation (3.1) with a dependent variable that equals 1 when an individual reports chest/breathing problems, asthma, or bronchitis.

Questions in the BHPS also ask about other diseases such as skin allergies, digestive problems, and epilepsy. These health problems are not likely to be correlated with smoking and the estimated effect of quitting on these problems should generate insignificant coefficient estimates if the treatment effect is well identified and does not contains confounding factors or reverse causation (e.g., if only generally healthy individuals quit smoking, estimated coefficient effects would capture difference in overall health status between the two groups, and would not be driven by smoking cessation). Therefore, I estimate the treatment effects on these variables as a falsification test and expect the changes in these health variables will not be related to smoking cessation.

Table 3.4 shows the results from the robustness checks. The first two columns show the results using breathing problem as the relevant health outcome. As shown, the estimated coefficients closely resemble the earlier results for self-reported health status. Note that the dependent variable is now equal to one when an individual reports respiratory problems. Smoking cessation reduces the likelihood of reporting this health problem by 19 to 20 per- 
centage points, and the treatment effects are reduced by prior smoking intensity and tenure, as expected. Using the average number of cigarettes smoked and the smoking tenure for each quitter, the average treatment effect is a 4 to 5 percentage point decrease in the likelihood of reporting respiratory problems. This can be interpreted as a $30 \%$ reduction in reported respiratory problems from the average reported rate $(13.3 \%)$ for a quitter before quitting.

The next 6 columns show the results from the falsification tests. For all the alternative health outcomes, the estimated coefficients are not significantly different from zero: smoking cessation has no impact on skin allergies, digestive problems, and epilepsy.

The main results are generally robust to these alternative specifications. Improved health status is more likely to be caused by smoking cessation through an improvement of the respiratory system. Smoking cessation has no impact on unrelated diseases, as expected.

\subsection{Discussion}

The estimated effects of smoking cessation in this paper only show a 5 to 6 percentage point, or $8 \%$, increase in positive self-reported health; this is smaller than reported in previous research. For example, Segovia et al. (1989) reports $22 \%$ increases in positive health for a former smokers one year after quitting compared to current smokers with 11-15 cigarette smoked. However, this finding does not address any empirical challenges related to estimating a causal relationship. As mentioned above, this paper uses appropriate control groups generated by propensity score matching, and successfully addresses the reverse causation problem with a large, nationally representative sample. This paper also controls for other individual behavior rather than smoking, which affects health outcomes when applying a matching technique.

Due to data limitations, this paper uses self-reported health as a health outcome. Benjamins et al. (2004) looked at the relationship between self-reported health and mortality rates by specific causes of death. This result is useful for relating the estimated effects in this paper to mortality rates, since smoking cessation has a positive impact on health through improvements in the respiratory system, as shown above. I focus only on changes in health 
status from fair to good to deal with differences in health measures ${ }^{5}$, and this is the main variation in the dependent variable in this paper ${ }^{6}$. From the findings in Benjamins et al. (2004), mortality rates caused by respiratory disease declined by $30 \%$ when an individual's health moved from fair to good. Using the estimated treatment effects in this paper, a $5 \%$ increase in positive self-reported health, smoking cessation would be associated with only a $1.5 \%$ decrease in mortality rates. This estimated effect on mortality rates is also smaller than previous findings, which generally report 10 to $30 \%$ decreases in mortality rates (Doll and Peto, 1976; Hammond, 1966; Kahn, 1966; Carstensen et al., 1987).

As mentioned above, Contoyannis and Jones (2004) and Balia and Jones (2008) are the first two papers which estimate a causal relationship between smoking (and other behavior) and health by applying a recursive multivariate probit model. Both papers argue that smoking increases mortality rates by $22 \%$ and generates $15 \%$ more poor self-reported health outcomes. Although these papers focused on the effects of smoking on health outcomes, not smoking cessation, the estimated treatment effects in this paper are smaller than those reported in Contoyannis and Jones (2004) and Balia and Jones (2008).

U.S. Department of Health and Human Services (1990) reported hypothetical disease incidence rates for current, former and never smokers, shown in Figure 3.2. Across all age groups, current smokers have higher disease incidence rates than never smokers. This figure shows three different hypothetical outcomes for a former smoker after quitting: smoking cessation does not change disease incidence rates (Curve A), smoking cessation reduces disease incidence rates but the rates stay between current smokers and never smokers (Curve $\mathrm{B}$ ), and the rates decline quickly and converge to the rates for never smokers (Curve C). From previous empirical findings, U.S. Department of Health and Human Services (1990) concluded that the decline in the risk of death for a former smoker begins after quitting, continues for 10 to 15 years, and finally the risk drops to equal those who never smoked (Curve $\mathrm{C}$ in Figure 3.2). However, given previous findings and their empirical limitations,

\footnotetext{
${ }^{5}$ Benjamins et al. (2004) used a US sample while this paper uses a British sample. Also there are differences in health status measures: Benjamins et al. (2004)'s question asks whether an individual's health is excellent, very good, good, fair, and poor.

${ }^{6}$ The dependent variable is equal to one when an individual reports his/her health as excellent or good, and zero otherwise. Changing from very poor to excellent should be a rare outcome, so I only focus on changes from fair to good.
} 
the smaller estimated effects of smoking cessation in this paper would indicate that the risk of former smokers declines but would not converge to the risk of never smokers (Curve B in Figure 3.2). Even if convergence effects exist, the rate of convergence would be slower than previous findings suggest. Also, reverse causality would generate overestimated effects of smoking cessation, since former smokers tend to quit smoking when they have a health problem, and estimated effects capture changes in health from coincident poor health status.

This paper analyzed 10 BHPS waves due to data limitations in other waves of the survey. Access to only 10 years of observations on smoking behavior might prevent the estimation of long-term effects of smoking cessation since I can only track former smokers for 5 to 8 years after quitting. U.S. Department of Health and Human Services (1990) argues that the impact of cessation lasts for 10 to 15 years. Also, as the BHPS does not contain more detailed question on physical activity and drinking, I cannot control for the case where a former smoker engages in more healthy behaviors than quitting smoking. Questions on physical activity and drinking ask whether an individual does exercise (drinks) once a week, once in a month, several times in a yea,r and once in a year. This is not enough variation to determine whether former smokers changed his/her entire life style after quitting.

\subsection{Conclusion}

This paper estimates the effect of smoking cessation on health outcomes. A relatively large longitudinal data set from the British Household Panel Survey allows for a detailed analysis of the effects of smoking cessation. To address self-selection problems, the paper employs propensity score matching. Defining quitting smoking as the treatment group and inconsistent smokers as the control group, this paper finds a $8 \%$ increase in the probability of better self-reported health after quitting smoking. This estimated effect diminishes with the number of cigarettes smoked before quitting and smoking tenure.

While this paper is first to explore the causal relationship between smoking cessation and health by addressing self-selection bias and reverse causation problems, other empirical problems such as false reporting on smoking behavior, and other healthy behaviors that former smokers tend to take up after quitting still exist due to the data limitations. Ad- 
ditional future research on this topic is clearly needed, using better data sets if any exist. Tracking longer periods of smoking cessation is also important to determine the long-term causal effects of smoking cessation. 


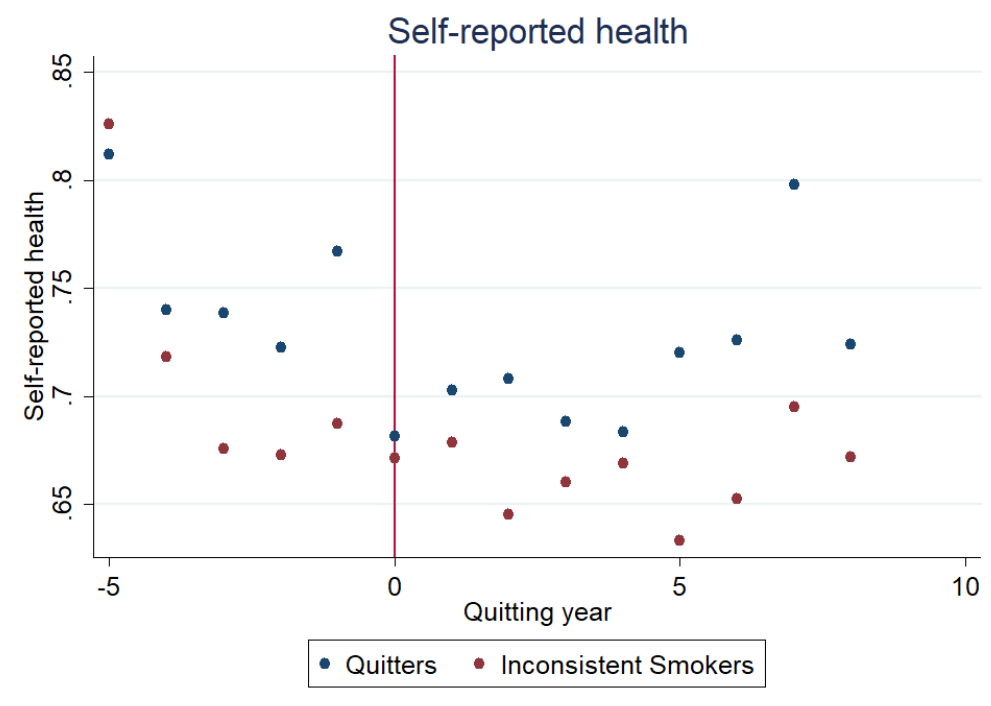

(a) Whole inconsistent smokers as a control group

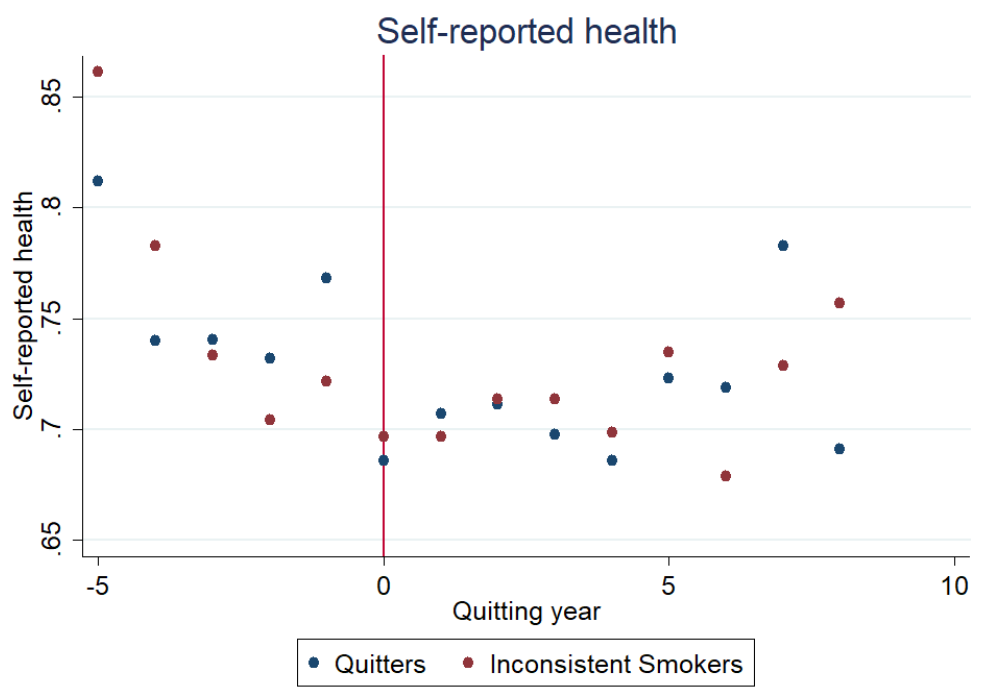

(b) Failure group as a control group

Figure 3.1: Changes in Health Outcomes 


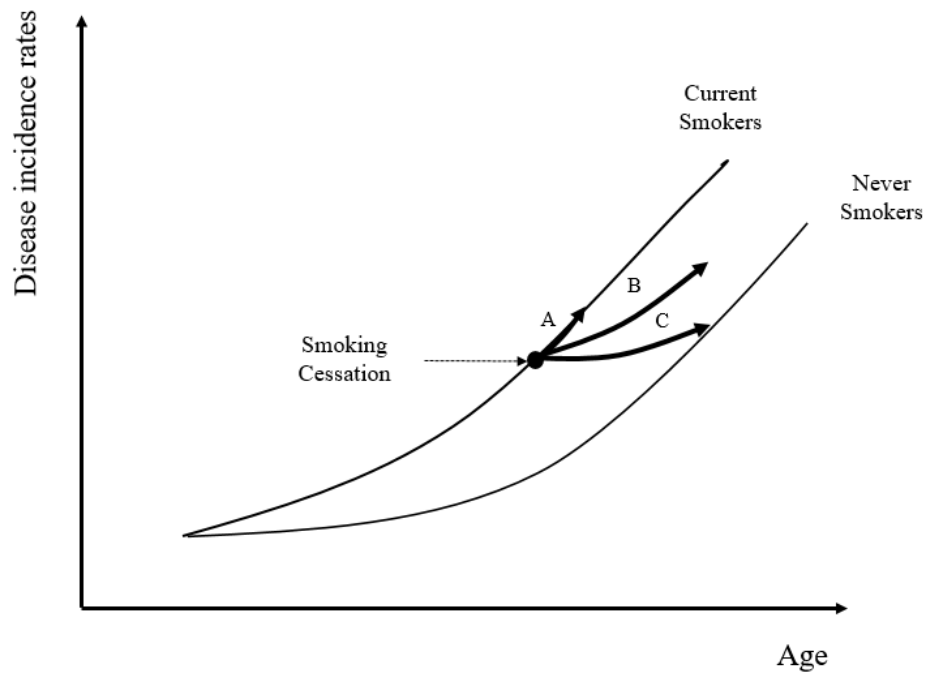

Figure 3.2: Hypothetical Disease Incidence Rates for Current, Former and Never Smokers, by Age 
Table 3.1: Summary Statistics - Smoking behavior 1999-2008

\begin{tabular}{lrr}
\hline & Frequency & $\%$ \\
\hline All time smoker & 967 & 12.13 \\
All time non-smoker & 2487 & 31.19 \\
Inconsistent smoker & 1031 & 12.93 \\
Quitter & 452 & 5.67 \\
Other & 3036 & 38.07 \\
\hline Total & 7973 & 100.00 \\
\hline
\end{tabular}


Table 3.2: Summary Statistics - Matching Covariates in 2000

\begin{tabular}{|c|c|c|c|c|}
\hline & \multirow[t]{2}{*}{ Quitters } & \multicolumn{2}{|c|}{ Whole inconsistent smokers } & \multirow[t]{2}{*}{ Failure group } \\
\hline & & Before matching & After matching & \\
\hline Annual income & 12851 & 12230 & 13075 & 13327 \\
\hline Age & 41.81 & $39.59 * *$ & 42.03 & $39.63^{* *}$ \\
\hline Female & 0.55 & 0.53 & 0.56 & 0.51 \\
\hline Marital status & 0.54 & 0.50 & 0.57 & 0.50 \\
\hline \# of child & 0.54 & $0.69^{* *}$ & 0.58 & 0.64 \\
\hline Further education & 0.41 & 0.35 & 0.42 & 0.39 \\
\hline Self-employed & 0.09 & 0.07 & 0.10 & 0.09 \\
\hline Retired & 0.14 & $0.10^{* *}$ & 0.12 & $0.09^{* *}$ \\
\hline $\mathrm{sc} 1$ & 0.38 & $0.31^{* * *}$ & 0.34 & $0.32^{*}$ \\
\hline $\mathrm{sc} 2$ & 0.43 & 0.46 & 0.34 & 0.48 \\
\hline $\mathrm{sc} 3$ & 0.21 & $0.26^{* *}$ & 0.25 & 0.22 \\
\hline drink & 0.36 & 0.40 & 0.34 & $0.42^{*}$ \\
\hline exercise & 0.54 & $0.48^{* *}$ & 0.52 & $0.46^{* *}$ \\
\hline \# of cigarettes & 7.06 & $9.68^{* * *}$ & $10.71^{* * *}$ & $8.24^{*}$ \\
\hline smoking tenure & 27.08 & 26.02 & 26.59 & $24.47^{* *}$ \\
\hline London & 0.08 & 0.06 & 0.07 & 0.06 \\
\hline Scotland & 0.18 & 0.22 & 0.19 & $0.24^{* *}$ \\
\hline Wales & 0.16 & 0.19 & 0.15 & $0.21^{*}$ \\
\hline North east & 0.03 & 0.02 & 0.04 & 0.04 \\
\hline North west & 0.10 & 0.09 & 0.12 & 0.08 \\
\hline Yorks & 0.07 & 0.08 & 0.07 & 0.08 \\
\hline East Midland & 0.04 & 0.06 & 0.04 & 0.06 \\
\hline West Midland & 0.06 & 0.06 & 0.05 & 0.05 \\
\hline East England & 0.08 & 0.07 & 0.08 & $0.05^{*}$ \\
\hline South east & 0.12 & 0.10 & 0.11 & 0.11 \\
\hline South west & 0.07 & $0.05^{*}$ & 0.07 & $0.04^{*}$ \\
\hline
\end{tabular}

$*$ indicates p-value from t-test for testing difference from quitter group.

${ }^{*} p<0.1,{ }^{* *} p<0.05,{ }^{* * *} p<0.01$, respectively 
Table 3.3: Difference-in-Differences Results

\begin{tabular}{lrr}
\hline DV & \multicolumn{3}{c}{ Self-reported health } \\
Control group & Whole inconsistent smokers & Failure group \\
\hline treated group & 0.023 & -0.010 \\
& $(0.026)$ & $(0.026)$ \\
quit & $0.275^{* * *}$ & $0.267^{* * *}$ \\
& $(0.039)$ & $(0.039)$ \\
quit*\# of cigarettes smoked & $-0.008^{* * *}$ & $-0.008^{* * *}$ \\
& $(0.002)$ & $(0.002)$ \\
quit*smoking tenure & $-0.005^{* * *}$ & $-0.005^{* * *}$ \\
& $(0.001)$ & $(0.001)$ \\
\hline
\end{tabular}

${ }^{*} p<0.1,{ }^{* *} p<0.05,{ }^{* * *} p<0.01$, respectively

Cluster-corrected standard errors at individual level in parentheses.

Year-fixed effects are included.

Table 3.4: Robustness Check

\begin{tabular}{|c|c|c|c|c|c|c|c|c|}
\hline \multirow{3}{*}{$\begin{array}{l}\text { DV } \\
\text { Control group }\end{array}$} & \multirow{2}{*}{\multicolumn{2}{|c|}{ Breathing problem }} & \multirow{2}{*}{\multicolumn{2}{|c|}{ Skin allergies }} & \multicolumn{4}{|c|}{ Falsification tests } \\
\hline & & & & & \multicolumn{2}{|c|}{ Digestive problem } & \multicolumn{2}{|c|}{ Epilepsy } \\
\hline & WIS & Failure & WIS & Failure & WIS & Failure & WIS & Failure \\
\hline \multirow[t]{2}{*}{ quit } & $-0.197 * * *$ & $-0.188^{* * *}$ & 0.012 & 0.014 & -0.039 & -0.039 & 0.017 & 0.018 \\
\hline & $(0.040)$ & $(0.040)$ & $(0.035)$ & $(0.035)$ & $(0.025)$ & $(0.025)$ & $(0.012)$ & $(0.012)$ \\
\hline \multirow[t]{2}{*}{ quit* \# of cigarettes smoked } & $0.004^{* *}$ & $0.004^{* *}$ & 0.001 & 0.001 & $0.003^{* *}$ & $0.003^{* *}$ & -0.001 & -0.001 \\
\hline & $(0.002)$ & $(0.001)$ & $(0.001)$ & $(0.001)$ & $(0.001)$ & $(0.001)$ & $(0.000)$ & $(0.000)$ \\
\hline \multirow[t]{2}{*}{ quit*smoking tenure } & $0.004^{* * *}$ & $0.004^{* * *}$ & 0.000 & -0.000 & 0.000 & 0.000 & -0.000 & -0.000 \\
\hline & $(0.001)$ & $(0.001)$ & $(0.001)$ & $(0.000)$ & $(0.001)$ & $(0.001)$ & $(0.000)$ & $(0.000)$ \\
\hline
\end{tabular}

${ }^{*} p<0.1,{ }^{* *} p<0.05,{ }^{* * *} p<0.01$, respectively

Cluster-corrected standard errors at individual level in parentheses.

Year-fixed effects are included.

WIS indicates the whole inconsistent smokers group 


\section{References}

Abadie, A., Diamond, A., and Hainmueller, J. (2010). Synthetic control methods for comparative case studies: Estimating the effect of california's tobacco control program. Journal of the American Statistical Association, 105(490):493-505.

Abadie, A., Diamond, A., and Hainmueller, J. (2015). Comparative politics and the synthetic control method. American Journal of Political Science, 59(2):495-510.

Abadie, A. and Gardeazabal, J. (2003). The economic costs of conflict: A case study of the basque country. The American Economic Review, 93(1):113-132.

Adda, J. and Cornaglia, F. (2006). Taxes, cigarette consumption, and smoking intensity. The American Economic Review, 96(4):1013-1028.

Adda, J. and Lechene, V. (2013). Health selection and the effect of smoking on mortality. The Scandinavian Journal of Economics, 115(3):902-931.

Albouy, D. and Lue, B. (2015). Driving to opportunity: Local rents, wages, commuting, and sub-metropolitan quality of life. Journal of Urban Economics, 89:74-92.

Ashford, J. (1973). Smoking and the use of the health services. British Journal of Preventive ES Social Medicine, 27(1):8-17.

Baade, R. A. (1996). Professional sports as catalysts for metropolitan economic development. Journal of Urban Affairs, 18(1):1-17.

Balarajan, R., Yuen, P., and Bewley, B. (1985). Smoking and state of health. BMJ, 291(6510):1682.

Balia, S. and Jones, A. M. (2008). Mortality, lifestyle and socio-economic status. Journal of Health Economics, 27(1):1-26.

Baumann, R., Ciavarra, T., Englehardt, B., and Matheson, V. A. (2012). Sports franchises, events, and city livability: an examination of spectator sports and crime rates. Economic and Labour Relations Review, 23(2):83-97. 
Becker, G. S. (1968). Crime and punishment: An economic approach. In The Economic Dimensions of Crime, pages 13-68. Springer.

Benjamins, M. R., Hummer, R. A., Eberstein, I. W., and Nam, C. B. (2004). Self-reported health and adult mortality risk: an analysis of cause-specific mortality. Social Science $\mathcal{E}$ Medicine, 59(6):1297-1306.

Bhattacharya, J., Goldman, D., and McCaffrey, D. (2006). Estimating probit models with self-selected treatments. Statistics in Medicine, 25(3):389-413.

Billings, S. B. and Depken II, C. A. (2011). Sport events and criminal activity: A spatial analysis. In Violence and Aggression in Sporting Contests, pages 175-187. Springer: New York, NY.

Bohn, S., Lofstrom, M., and Raphael, S. (2014). Did the 2007 legal arizona workers act reduce the state's unauthorized immigrant population? Review of Economics and Statistics, 96(2):258-269.

Bureau of the Census, U. S. (1985). 1982 Census of Retail Trade: Major Retail Centers in Standard Metropolitan Statistical Areas. Number v. 1 in 1982 Census of Retail Trade: Major Retail Centers in Standard Metropolitan Statistical Areas. U.S. Department of Commerce, Bureau of the Census.

Card, D. and Dahl, G. B. (2011). Family violence and football: The effect of unexpected emotional cues on violent behavior. Quarterly Journal of Economics, 126(1):103-143.

Carstensen, J. M., Pershagen, G., and Eklund, G. (1987). Mortality in relation to cigarette and pipe smoking: 16 years' observation of 25,000 swedish men. Journal of Epidemiology and Community Health, 41(2):166-172.

Chase, J. and Healey, M. (1995). The spatial externality effects of football matches and rock concerts: The case of Portman Road Stadium, Ipswich, Suffolk. Applied Geography, $15(1): 18-34$. 
Coates, D. and Humphreys, B. R. (2002). The economic impact of postseason play in professional sports. Journal of Sports Economics, 3(3):291-299.

Coates, D. and Humphreys, B. R. (2003a). The effect of professional sports on earnings and employment in the services and retail sectors in us cities. Regional Science and Urban Economics, 33(2):175-198.

Coates, D. and Humphreys, B. R. (2003b). The effect of professional sports on earnings and employment in the services and retail sectors in US cities. Regional Science and Urban Economics, 33(2):175-198.

Coates, D., Humphreys, B. R., et al. (2008). Do economists reach a conclusion on subsidies for sports franchises, stadiums, and mega-events? Econ Journal Watch, 5(3):294-315.

Contoyannis, P. and Jones, A. M. (2004). Socio-economic status, health and lifestyle. Journal of Health Economics, 23(5):965-995.

Cotti, C. and Tefft, N. (2011). Decomposing the relationship between macroeconomic conditions and fatal car crashes during the great recession: alcohol-and non-alcohol-related accidents. The BE Journal of Economic Analysis $\&$ Policy, 11(1).

Doll, R. and Peto, R. (1976). Mortality in relation to smoking: 20 years' observations on male british doctors. BMJ, 2(6051):1525-1536.

Doll, R., Peto, R., Boreham, J., and Sutherland, I. (2004). Mortality in relation to smoking: 50 years' observations on male british doctors. BMJ, 328(7455):1519.

Duranton, G. and Turner, M. A. (2011). The fundamental law of road congestion: Evidence from US cities. The American Economic Review, 101(6):2616-2652.

Gaynor, M., Laudicella, M., and Propper, C. (2012). Can governments do it better? merger mania and hospital outcomes in the English NHS. Journal of Health Economics, 31(3):528543.

Groothuis, P. A., Johnson, B. K., and Whitehead, J. C. (2004). Public funding of professional sports stadiums: Public choice or civic pride? Eastern Economic Journal, 30(4):515-526. 
Hammond, E. C. (1966). Smoking in relation to the death rates of one million men and women. National Cancer Institute Monograph, 19:127-204.

He, M. M. (2016). Driving through the great recession: Why does motor vehicle fatality decrease when the economy slows down? Social Science $\&$ Medicine, 155:1-11.

Holian, M. J. and Kahn, M. E. (2012). The impact of center city economic and cultural vibrancy on greenhouse gas emissions from transportation. Research Report 11-13, Mineta Transportation Institute, San Jose, CA.

Huang, H. and Humphreys, B. R. (2014). New sports facilities and residential housing markets. Journal of Regional Science, 54(4):629-663.

Humphreys, B. R. and Zhou, L. (2015). Sports facilities, agglomeration, and public subsidies. Regional Science and Urban Economics, 54:60-73.

Humphreys, D., Mason, C., and Pinch, S. (1983). The externality fields of football grounds: a case study of the Dell, Southampton. Geoforum, 14(4):401-411.

Jha, P., Ramasundarahettige, C., Landsman, V., Rostron, B., Thun, M., Anderson, R. N., McAfee, T., and Peto, R. (2013). 21st-century hazards of smoking and benefits of cessation in the united states. New England Journal of Medicine, 368(4):341-350.

Johnson, B. K., Groothuis, P. A., and Whitehead, J. C. (2001). The value of public goods generated by a major league sports team: The CVM approach. Journal of Sports Economics, 2(1):6-21.

Johnson, B. K., Mondello, M. J., and Whitehead, J. C. (2007). The value of public goods generated by a National Football League team. Journal of Sport Management, 21(1):123.

Kahn, H. A. (1966). The dorn study of smoking and mortality among us veterans: report on eight and one-half years of observation. National Cancer Institute Monograph, 19:1-126.

Kalist, D. E. and Lee, D. Y. (2016). The national football league: Does crime increase on game day? Journal of Sports Economics, 17(8):863-882. 
Krueger, A. B., Kahneman, D., Schkade, D., Schwarz, N., and Stone, A. A. (2009). National time accounting: The currency of life. In Kreuger, A. B., editor, Measuring the Subjective Well-being of Nations: National Accounts of Time Use and Well-being, pages 9-86. University of Chicago Press.

Lasley, P., Lomax, T., Eisele, W., and Schrank, D. (2014). Developing a total peak period travel time performance measure: An updated concept paper. Transportation Research Record: Journal of the Transportation Research Board, (2420):15-22.

Lechner, M. (2009). Long-run labour market and health effects of individual sports activities. Journal of Health Economics, 28(4):839-854.

Marie, O. (2016). Police and thieves in the stadium: measuring the (multiple) effects of football matches on crime. Journal of the Royal Statistical Society: Series A (Statistics in Society), 179(1):273-292.

Munasib, A. and Rickman, D. S. (2015). Regional economic impacts of the shale gas and tight oil boom: A synthetic control analysis. Regional Science and Urban Economics, 50:1-17.

Munyo, I. and Rossi, M. A. (2013). Frustration, euphoria, and violent crime. Journal of Economic Behavior \& Organization, 89:136-142.

National Sports Law Institute of Marquette University Law School (2013). Sports facility reports, volume 14 .

Oakes, T. W., Friedman, G. D., Seltzer, C. C., Siegelaub, A., and Collen, M. F. (1974). Health service utilization by smokers and nonsmokers. Medical Care, pages 958-966.

Owen, J. G. (2006). The intangible benefits of sports teams. Public Finance and Management, 6(3):321-345.

Pyun, H. and Hall, J. C. (2016). Does the presence of professional football cause crime in a city? evidence from Pontiac, Michigan. Working paper no. 16-02, West Virginia University, Department of Economics. 
Rappaport, J. (2016). Productivity, congested commuting, and metro size. Research Working Paper RWP 16-3, Federal Reserve Bank of Kansas City.

Rees, D. I. and Schnepel, K. T. (2009). College football games and crime. Journal of Sports Economics, 10(1):68-87.

Salon, D., Boarnet, M. G., Handy, S., Spears, S., and Tal, G. (2012). How do local actions affect VMT? a critical review of the empirical evidence. Transportation Research Oart D: Transport and Environment, 17(7):495-508.

Segovia, J., Bartlett, R. F., and Edwards, A. C. (1989). The association between selfassessed health status and individual health practices. Canadian Journal of Public Health, $80(1): 32-37$.

Semykina, A. and Wooldridge, J. M. (2010). Estimating panel data models in the presence of endogeneity and selection. Journal of Econometrics, 157(2):375-380.

Siegfried, J. and Zimbalist, A. (2000). The economics of sports facilities and their communities. The Journal of Economic Perspectives, pages 95-114.

Small, K. A. and Verhoef, E. T. (2007). The Economics of Urban Transportation. Routledge.

The Washington Post (2008). Paying for the ballpark. [Online; posted 24-March-2008].

U.S. Department of Health and Human Services (1990). The Health Benefits of Smoking Cessation: A Report of the Surgeon General. Department of Health and Human Services, Centers for Disease Control and Prevention, National Center for Chronic Disease Prevention and Health Promotion, Office on Smoking and Health, Rockville, MD, USA.

U.S. Department of Health and Human Services (2014). The Health Consequences of Smoking? 50 Years of Progress: A Report of the Surgeon General. Department of Health and Human Services, Centers for Disease Control and Prevention, National Center for Chronic Disease Prevention and Health Promotion, Office on Smoking and Health, Atlanta, GA, USA. 
Vogt, T. M. and Schweitzer, S. O. (1985). Medical costs of cigarette smoking in a health maintenance organization. American Journal of Epidemiology, 122(6):1060-1066.

Wooldridge, J. M. (1995). Selection corrections for panel data models under conditional mean independence assumptions. Journal of Econometrics, 68(1):115-132.

Yu, Y., Mckinney, C. N., Caudill, S. B., and Mixon Jr, F. G. (2016). Athletic contests and individual robberies: an analysis based on hourly crime data. Applied Economics, 48(8):723-730. 